\title{
The Arabidopsis kinase-associated protein phosphatase controls internalization of the somatic embryogenesis receptor kinase 1
}

\author{
Khalid Shah, ${ }^{1}$ Eugenia Russinova, Theodorus W.J. Gadella, Jr., ${ }^{2}$ Joost Willemse, \\ and Sacco C. de Vries ${ }^{3}$ \\ Laboratory of Molecular Biology, Department of Plant Sciences, Wageningen University, \\ 6703 HA Wageningen, The Netherlands
}

The AtSERK1 protein is a plasma membrane-located LRR receptor-like serine threonine kinase that is transiently expressed during plant embryogenesis. Our results show that AtSERK1 interacts with the kinase-associated protein phosphatase (KAPP) in vitro. The kinase interaction (KI) domain of KAPP does not interact with a catalytically inactive kinase mutant. Using mutant AtSERK1 proteins in which Thr 462, Thr 463, and Thr 468 in the A-loop of the AtSERK1 kinase domain were replaced by alanines, we show that phosphorylation status of the receptor is involved in interaction with KAPP. KAPP and AtSERK1 cDNAs were fused to two different variants of green fluorescent protein (GFP), the yellow fluorescent protein (YFP) or the cyan fluorescent protein (CFP). Both KAPP and AtSERK1 proteins are found at the plasma membrane. Our results show that AtSERK1-CFP becomes sequestered into intracellular vesicles when transiently coexpressed with KAPP-YFP proteins. AtSERK1 ${ }^{\text {T463A }}$-CFP and AtSERK1 ${ }^{3 T \rightarrow A}-$ CFP proteins were partially sequestered intracellularly in the absence of KAPP-YFP protein, suggesting an active role for KAPP dephosphorylation of threonine residues in the AtSERK1 A-loop in receptor internalization. The interaction between the KAPP-CFP/YFP and AtSERK1-CFP/YFP fusion proteins was investigated with fluorescence spectral imaging microscopy (FSPIM). Our results show that AtSERK1-CFP and KAPP-YFP proteins are colocalized at the plasma membrane but only show fluorescence energy transfer (FRET) indicative of physical interaction in intracellular vesicles. These results suggest that KAPP is an integral part of the AtSERK1 endocytosis mechanism.

[Key Words: Interaction; phosphorylation; localization; fluorescence; phosphatase]

Received December 5, 2001; revised version accepted May 8, 2002.

Dephosphorylation of transmembrane receptor kinases catalyzed by phosphatases is an essential control element in receptor-mediated signaling. Two major groups, tyrosine kinases and phosphatases, and serine/threonine kinases and phosphatases are distinguished /Cohen 1989). Phosphatases that dephosphorylate serine and threonine residues are encoded by the PPP and the PPM gene families that are defined by distinct amino acid sequences and crystal structures. The PPP family includes the signature phosphatases, PP1, PP2A, and PP2B whereas the PPM family comprises the $\mathrm{Mg}^{2+}$-dependent

Present addresses: ${ }^{1}$ Department of Neurology, Massachusetts General Hospital, Harvard Medical School, Charlestown, MA 02129, USA; ${ }^{2}$ Section of Molecular Cytology, Swammerdam Institute for Life Sciences, 1098 SM Amsterdam, The Netherlands.

${ }^{3}$ Corresponding author.

E-MAIL sacco.devries@mac.mb.wau.nl; FAX 31-317-483-584.

Article and publication are at http://www.genesdev.org/cgi/doi/10.1101/ gad.220402. protein phosphatases that include PP2C and pyruvate dehydrogenase phosphatase (Cohen 1997).

Plant receptor-like kinases (RLKs) are classified into several groups based on the structural features of the predicted extracellular domain. To date, leucine-rich repeat (LRR)-RLKs comprise the largest class of RLKs (Torii 2000), and most of them were shown to be serine/ threonine kinases. Examples are the CLAVATA1 (CLV1) gene that controls cell proliferation in the shoot meristem (Clark et al. 1997), the ERECTA gene that regulates organ shape (Torii et al. 1996), and the BRI1 gene, involved in brassinosteroid signaling ( $\mathrm{Li}$ and Chory 1997). There is also evidence for phosphatases that interact with different RLKs. Many of the RLKs have been shown to interact with a type $2 \mathrm{C}$ protein phosphatase called the kinase-associated protein phosphatase (KAPP) (Stone et al. 1994; Torii 2000).

KAPP is comprised of an amino terminal type 1 signal anchor followed by a kinase interaction (KI) domain and a C-terminal type $2 \mathrm{C}$-protein phosphatase catalytic do- 
main (Stone et al. 1994). Type 2C-protein phosphatases are characterized by their substrate preference, insensitivity to various protease inhibitors, and an absolute requirement for divalent cations (Shenolikar and Nairn 1991). The physical interaction between KAPP and the RLKs is thought to be important for their roles in signal transduction (Li et al. 1999). Both genetic and biochemical approaches have shown that KAPP interacts in vivo with RLKs, suggesting that KAPP negatively regulates RLK signaling (Williams et al. 1997; Stone et al. 1998). The reduction of KAPP transcript accumulation in an intermediate clv1 mutant shows the suppression of the mutant phenotype, the degree of suppression being inversely correlated with KAPP mRNA levels. KAPP also coimmunoprecipitates with CLV1 in plant extracts derived from meristematic tissue (Trotochaud et al. 1999). KAPP has also been shown to interact in vitro with the CLV1 kinase domain (Williams et al. 1997), the HAESA kinase domain (Stone et al. 1994), and the KIKI kinase domain (Braun et al. 1997). The KI domain of KAPP binds RLKs in vitro in a phosphorylation-dependent manner and does not bind kinase-inactive mutants of RLKs.

Somatic embryogenesis is the process whereby somatic cells can develop into plants via characteristic morphological stages. In cultured Daucus carota suspension cells, the SERK (somatic embryogenesis receptor kinase) gene encoding a leucine-rich repeat (LRR)-RLK was found to be a marker for single somatic cells capable of forming embryos (Schmidt et al. 1997). During somatic and zygotic embryogenesis, SERK expression continues up to the early globular stage and is absent in later stages of embryo development. The most closely related Arabidopsis AtSERK1 gene encodes a receptor kinase that is expressed during ovule development and early embryogenesis (Hecht et al. 2001) and has serine/threonine kinase activity (Shah et al. 2001a). The predicted AtSERK1 protein contains an N-terminal leucine zipper (LZ), five leucine-rich repeats (LRRs) and a proline-rich region in its predicted extracellular domain. This is followed by a single transmembrane domain that is attached to an intracellular kinase domain with all 11 conserved subdomains found in serine/threonine kinases (Shah et al. 2001a). We showed previously that Thr 468 in the AtSERK1 A-loop is essential for transphosphorylating common substrates like casein and MBP (Shah et al. 2001a).

Different spectral variants of GFP exhibiting yellow or cyan fluorescence (YFP and CFP, respectively) provide an opportunity to label proteins with two different fluorophores within the same living cell (Rizzuto et al. 1996). YFP and CFP retain their characteristic fluorescence when fused to other protein sequences, allowing fluorescence microscopy to visualize the GFP-fusion protein localization (Carey et al. 1996; Gerdes et al. 1996; Ludin et al. 1996) and the interaction between two proteins by fluorescence resonance energy transfer (FRET) (Sorkin et al. 2000) in intact cells. FRET is a quantum mechanical process by which the excitation energy is transferred from a donor fluorophore to an appropriate acceptor fluorophore. FRET is manifested in different ways: a decrease in donor fluorescence quantum yield, a decreased donor fluorescence lifetime, and an increased (sensitized) emission acceptor fluorescence emission (if the acceptor is a fluorophore) (Jovin and Arndt-Jovin 1989; Gadella et al. 1999|. In our previous studies with AtSERK1-YFP/CFP proteins using FSPIM, we showed that AtSERK1 is expressed mainly as a monomer at the plasma membrane (Shah et al. 2001b).

In the present study we investigated whether the KAPP protein is involved in AtSERK1 signaling. Our results suggest that KAPP is required for AtSERK1 endocytosis.

\section{Results}

Interaction between AtSERK1 and KAPP proteins

The AtSERK1-GST, KAPP-GST, AtSERK1-YFP/CFP, and KAPP-YFP/CFP constructs used are shown in Figure 1. To determine whether the KAPP KI domain biochemically and physically interacted with AtSERK1 in vitro, both the kinase domain of AtSERK1 and the KI domain of KAPP were expressed as GST fusion proteins in $E$. coli. The affinity-purified AtSERK $1^{\text {kin }}$ and $\mathrm{KAPP}^{\mathrm{KI}}$ fusion proteins were then used in phosphorylation assays (Fig. 2A). Increasing phosphosphorylation of AtSERK1 $1^{\text {kin }}$ was seen on increasing its concentration (Fig. 2A, lanes 1-3). KAPP ${ }^{\mathrm{KI}}$ was phosphorylated in the presence of AtSERK1 ${ }^{\text {kin }}$ protein (Fig. 2A, lanes 4-8). Since both proteins are substrates for phosphorylation, the level of phosphorylation was determined as a function of protein concentration (Fig. 2A). Above an approximately equimolar ratio, increasing amounts of KAPP ${ }^{\mathrm{KI}}$ led to an increase in the phosphorylation of $\mathrm{KAPP}^{\mathrm{KI}}$ and a decreased phosphorylation of AtSERK $1^{\text {kin }}$ (Fig. 2A, cf. lanes 6 and 3). The KAPP ${ }^{\mathrm{KI}}$ phosphorylation was less affected when the AtSERK $1{ }^{\text {kin }}$ protein concentration was decreased in the incubation mix (Fig. 2A, cf. lanes 7 and 8 with lanes 4 and 5). KAPP ${ }^{\mathrm{KI}}$ protein was unable to phosphorylate alone (Fig. 2A, lane 9). This demonstrates that KAPP is a substrate for AtSERK $1^{\text {kin }}$ and that the two proteins biochemically interact in vitro.

AtSERK1 A-loop that is formed from subdomains VII and VIII has three threonine residues that are potential phosphorylation sites (Shah et al. 2001a). To determine whether the interaction between AtSERK1 ${ }^{\text {kin }}$ and KAPP ${ }^{\mathrm{KI}}$ is phosphorylation-dependent, we tested the AtSERK1 ${ }^{\text {kin }}$, the catalytically inactive AtSERK $1^{\mathrm{K} 330 \mathrm{E}}$, and the AtSERK $1^{3 \mathrm{~T} \rightarrow \mathrm{E}}$ mutant proteins in which three threonine residues in the AtSERK1 A-loop have been mutated, for their association with $\mathrm{KAPP}^{\mathrm{KI}}$ by in vitro binding assays. The AtSERK $1{ }^{\text {kin }}$ proteins were incubated in the presence of unlabeled ATP and transferred after electrophoresis onto a membrane and incubated with $\left[\gamma-{ }^{32} \mathrm{P}\right]$ ATP-labeled $\mathrm{KAPP}^{\mathrm{KI}}$ probe. AtSERK1 ${ }^{\text {kin }}$ (Fig. 2B, lane 1) interacted with $\mathrm{KAPP}^{\mathrm{KI}}$ probe, and no interaction was observed between the KAPP ${ }^{\mathrm{KI}}$ and the AtSERK $1^{\mathrm{K} 330 \mathrm{E}}$ and AtSERK $1^{3 \mathrm{~T} \rightarrow \mathrm{E}}$ mutant (Fig. 2B, lanes 2 and 3). To further test whether the interaction between $A t S E R K 1^{\text {kin }}$ and $\mathrm{KAPP}^{\mathrm{KI}}$ was dependent on the phosphorylation state of the AtSERK $1^{\text {kin }}$ protein, the AtSERK $1^{\text {kin }}$ was treated 

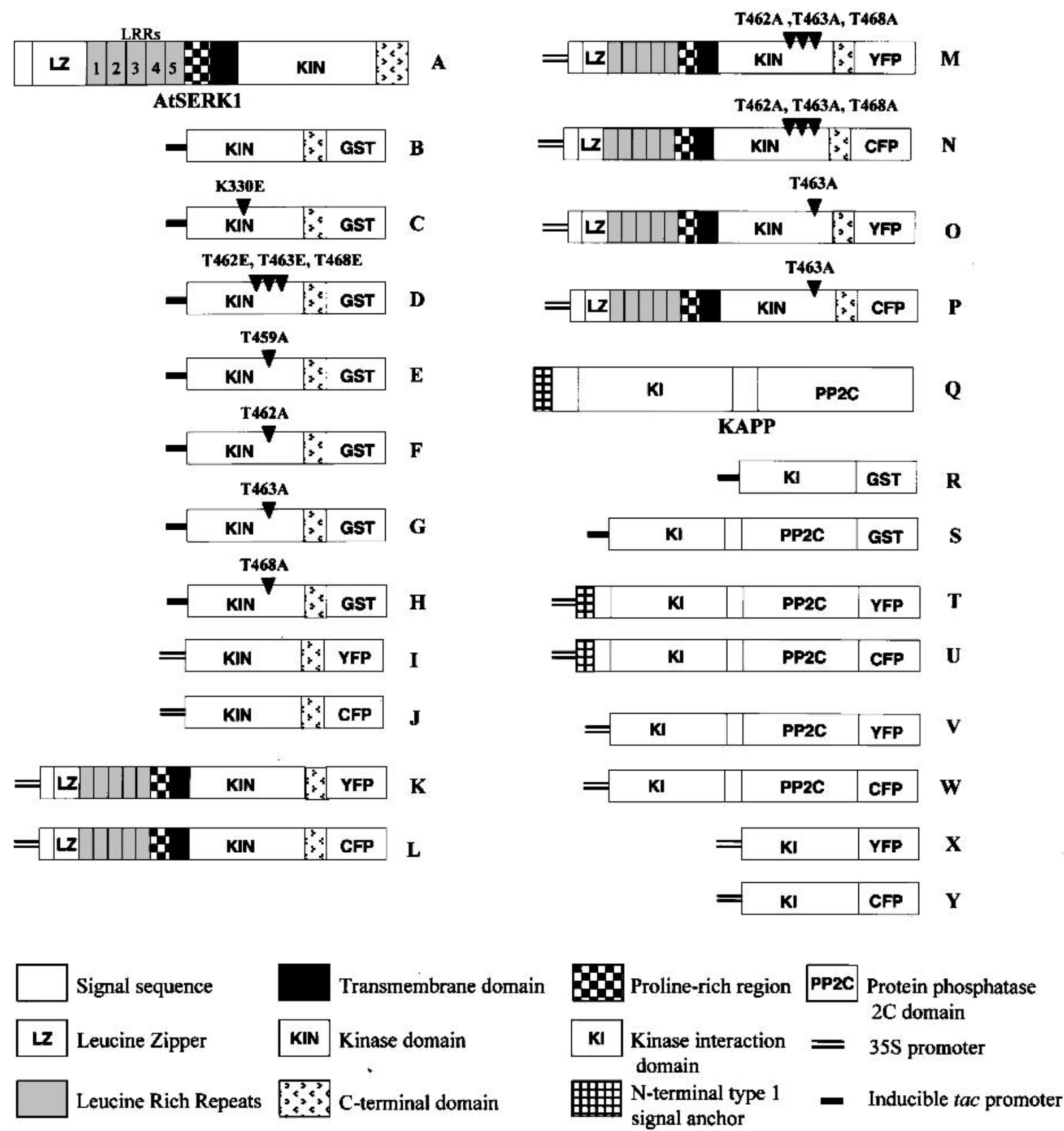

Figure 1. Plasmid constructs used. Different domains of AtSERK1 (A) and KAPP (Q) (Stone et al. 1994). AtSERK1-GST fusion (B-H) and KAPP-GST fusion $(R, S)$ constructs used for expression in E. coli. AtSERK1-CFP/YFP fusion $(I-P)$ and KAPP-CFP/YFP fusion (T-Y) constructs used for transient expression in plant protoplasts. The AtSERK1-GST transgenes were constructed in the PGEX-4T1 vector under the control of the inducible tac promoter. AtSERK1 kin $(B)$ contains cDNA encoding for the intracellular kinase domain of AtSERK1 as an N-terminal fusion with the GST. Site-directed mutagenesis in the AtSERK ${ }^{\text {kin }}$ construct generated mutant constructs

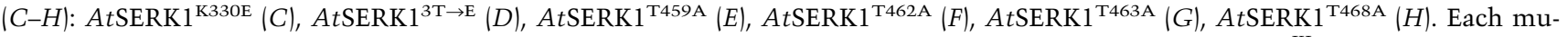
tation is noted at the top of the construct. The KAPP-GST transgenes were constructed similarly. The KAPP ${ }^{\mathrm{KI}}(R)$ encodes only the kinase interaction domain of KAPP fused to GST. KAPP ${ }^{-S A}(S)$ contains cDNA encoding for the full-length KAPP missing only the N-terminal signal anchor fused to GST. The AtSERK1-YFP/CFP transgenes were constructed in the PMON999 vector under the control of the 35S promoter. AtSERK1-YFP/CFP $(K, L)$ contains cDNA encoding for the full-length AtSERK1 as a C-terminal fusion with the YFP/CFP genes. AtSERK $1^{\text {kin }}$-YFP/CFP encodes only the intracellular kinase domain of AtSERK1 fused to YFP/CFP $(I, J)$. The AtSERK1 $1^{3 \mathrm{~T} \rightarrow \mathrm{A}_{-} \text {YFP/CFP and AtSERK1 }}{ }^{\mathrm{T} 463 \mathrm{~A}}$-YFP/CFP constructs contain the full-length AtSERK1 in which Thr 462, Thr 463, Thr 468 in $A t S E R K 1^{3 \mathrm{~T} \rightarrow \mathrm{A}}$ or Thr 463 in AtSERK1 $1^{\mathrm{T} 463 \mathrm{~A}}$ were mutated into alanine residues and fused to YFP/CFP genes $(M-P)$. The KAPPYFP/CFP transgenes were constructed similarly. KAPP-YFP/CFP $(T, U)$ contains cDNA encoding for the full-length KAPP as a Cterminal fusion with the YFP/CFP genes. KAPP ${ }^{-S A}$-YFP/CFP $(V, W)$, the same as $T$ and $U$ but missing the $\mathrm{N}$-terminal signal anchor. $\mathrm{KAPP}{ }^{\mathrm{KI}}$-YFP/CFP $(X, Y)$ encodes only the kinase interaction domain of KAPP fused to YFP/CFP. 
A
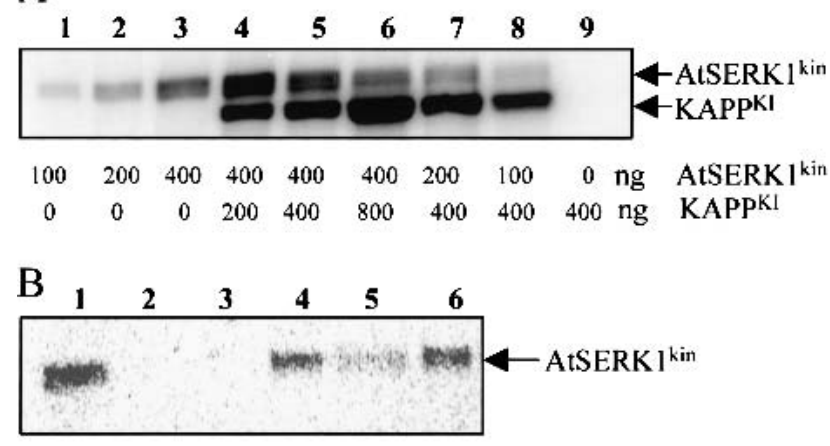

C

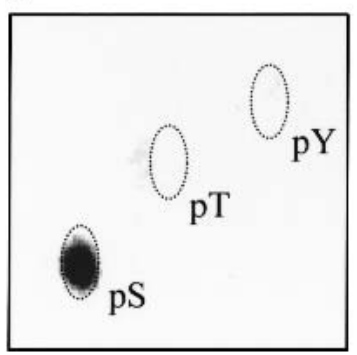

Figure 2. In vitro KAPP interactions with $A t S E R K 1^{\text {kin }}$. (A) Bacterially produced, affinity-purified AtSERK $1^{\text {kin }}$ and KAPP ${ }^{\mathrm{KI}}$ proteins were purified, and aliquots ranging from 0 to $800 \mathrm{ng}$ were used. Different concentrations of AtSERK1 ${ }^{\text {kin }}(t o p)$ and KAPP ${ }^{\mathrm{KI}}$ (bottom) proteins were incubated with $\left[\gamma_{-}{ }^{32} \mathrm{P}\right] \mathrm{ATP}$ as described in Materials and Methods. After separation on 10\% SDS-PAGE, the gels were autoradiographed using a PhosphorImager. (B) Immobilized KAPP ${ }^{\mathrm{KI}}$ protein was phosphorylated with 10 units of bovine heart muscle kinase (Sigma) in the presence of $\left[\gamma^{-32} \mathrm{P}\right]$ ATP. The resulting eluent was used to probe the nitrocellulose filter containing AtSERK1 ${ }^{\text {kin }}$ (lane 1), AtSERK1 ${ }^{\mathrm{K} 330 \mathrm{E}}$ (lane 2), AtSERK $1^{3 \mathrm{~T} \rightarrow \mathrm{E}}$ (lane 3), AtSERK $1^{\text {kin }}$ treated with alkaline phosphatase inhibitor (API) (lane 4), AtSERK1 ${ }^{\text {kin }}$ treated with alkaline phosphatase (AP) (lane 5), and AtSERK $1^{\text {kin }}$ treated with AP and AP1 (lane 6), and then allowed to phosphorylate in the presence of ATP and $\mathrm{MgCl}_{2}$. The filters were autoradiographed using a PhosphorImager. $(C)$ Phosphoaminoacid analysis of the $\mathrm{HCl}$ hydrolyzed $\mathrm{KAPP}^{\mathrm{KI}}$ protein phosphorylated by AtSERK ${ }^{\text {kin }}$. The hydrolyzed protein was spotted onto a TLC plate and resolved by ascending chromatography in two dimensions. The autoradiograph of the phosphorylated amino acids and the position of the standard amino acids visualized by $0.25 \%$ ninhydrin spray are phosphoserine $(\mathrm{pS})$, phosphothreonine $(\mathrm{pT})$, and phosphotyrosine $(\mathrm{pY})$, respectively.

with alkaline phosphatase (AP) alone or with AP in addition to the AP inhibitor (API) and incubated in the presence of unlabeled ATP. KAPP ${ }^{\mathrm{KI}}$ showed a reduced interaction with the dephosphorylated (AP-treated) AtSERK1 ${ }^{\text {kin }}$ (Fig. 2B, lane 5) compared to the phosphorylated AtSERK1 1 kin (Fig. 2B, lane 1) or both the AP- and API-treated AtSERK1 ${ }^{\text {kin }}$ (Fig. 2B, lane 6). The phosphoaminoacid analysis performed on the KAPP ${ }^{\mathrm{KI}}$ phosphorylated by AtSERK1 ${ }^{\text {kin }}$ protein showed that it was phosphorylated on serines (Fig. 2C).

These results show that KAPP ${ }^{\mathrm{KI}}$ interacts with AtSERK1 ${ }^{\text {kin }}$ in a phosphorylation-dependent manner.
Furthermore, the threonine residues in the AtSERK1 Aloop seem to play an essential role in the transphosphorylation of the KAPP ${ }^{\mathrm{KI}}$ protein.

In a previous work, we showed that the effect on the phosphorylation activity was similar when AtSERK1 Aloop threonines were mutated to either glutamic acid residues or to alanine residues (Shah et al. 2001a). To investigate the role of individual threonine residues in the AtSERK1 A-loop in AtSERK1 ${ }^{\text {kin }}$-KAPP ${ }^{\mathrm{KI}}$ transphosphorylation, all four threonine residues in the AtSERK1 A-loop, that is, Thr 459, Thr 462, Thr 463, and Thr 468 were mutagenized individually to alanine residues. The transphosphorylation assays with affinity-purified $\mathrm{KAPP}^{\mathrm{KI}}$ and AtSERK1 ${ }^{\text {kin }}$ threonine mutant proteins showed that there was a reduced transphosphorylation of $\mathrm{KAPP}^{\mathrm{KI}}$ when incubated with AtSERK1 ${ }^{\mathrm{T} 459 \mathrm{~A}}$ (Fig. 3A, lane 2) compared to $\mathrm{KAPP}^{\mathrm{KI}}$ phosphorylation by AtSERK1 ${ }^{\text {kin }}$ (Fig. 3A, lane 1). KAPP ${ }^{\mathrm{KI}}$ was not phosphorylated when incubated with AtSERK1 ${ }^{\mathrm{T} 462 \mathrm{~A}}$ (Fig. 3A, lane 3) or AtSERK1 ${ }^{\mathrm{T} 463 \mathrm{~A}}$ (Fig. 3A, lane 4) or AtSERK1 ${ }^{\mathrm{T} 468 \mathrm{~A}}$
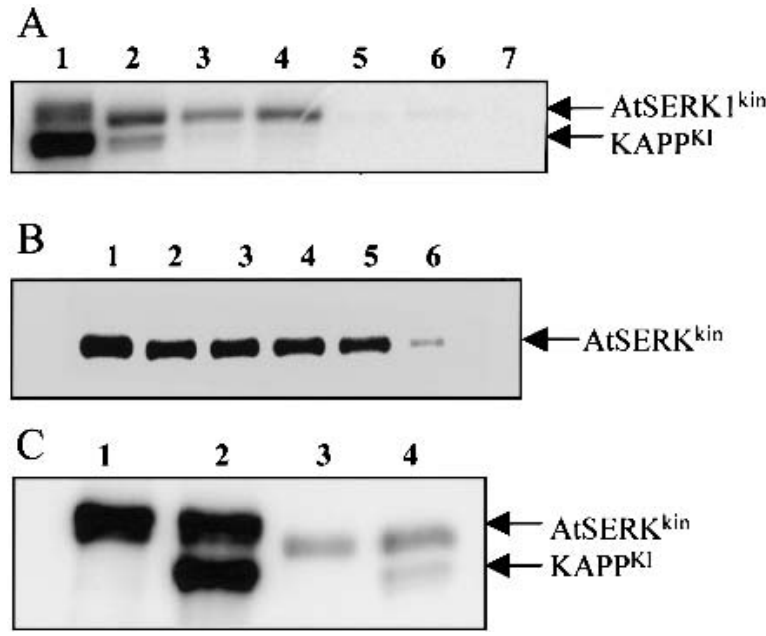

Figure 3. (A) KAPP interactions with AtSERK1 $1^{\text {kin }}$ mutant proteins. Five hundred nanograms of affinity-purified AtSERK1 1 ${ }^{\text {kin }}$ or AtSERK $1^{\text {kin }}$ mutant proteins were incubated with $\mathrm{KAPP}^{\mathrm{KI}}$ protein in the presence of $\left[\gamma^{-}{ }^{32} \mathrm{P}\right] \mathrm{ATP}$ in a phosphorylation assay as described in Materials and Methods. After separation on $10 \%$ SDS-PAGE, the gels were autoradiographed using a PhosphorImager. AtSERK $1^{\text {kin }}$ and AtSERK $1^{\text {kin }}$ mutants $(t o p)$ and KAPP ${ }^{\mathrm{KI}}$ (bottom) proteins are shown. AtSERK1 ${ }^{\text {kin }}$ (lane 1), AtSERK1 ${ }^{\mathrm{T} 459 \mathrm{~A}}$ (lane 2), AtSERK1 ${ }^{\mathrm{T} 462 \mathrm{~A}}$ (lane 3), AtSERK1 ${ }^{\mathrm{T} 463 \mathrm{~A}}$ (lane 4), AtSERK1 ${ }^{\mathrm{T} 468 \mathrm{~A}}$ (lane 5), AtSERK1 ${ }^{3 \mathrm{~T} \rightarrow \mathrm{E}}$ (lane 6), and AtSERK1 ${ }^{\mathrm{K} 330 \mathrm{E}}$ (lane 7). (B) Dephosphorylation of AtSERK1 by KAPP protein. Matrix-bound AtSERK1 ${ }^{\text {kin }}$ was phosphorylated by $\left[\gamma_{-}{ }^{32} \mathrm{P}\right] \mathrm{ATP}$ as described in Materials and Methods. The phosphorylated AtSERK1 ${ }^{\text {kin }}$ (lane 1) was incubated with KAPP ${ }^{-S A}$ protein and the aliquots were taken after 30, 60, 90, 120, and 240 min (lanes 2-6). After separation on 10\% SDS-PAGE, the gels were autoradiographed using a PhosphorImager. $(C)$ Phosphorylation of a mix of $500 \mathrm{ng}$ of each AtSERK $1^{\text {kin }}$ and KAPP proteins in the presence of $\left[\gamma^{32} \mathrm{P}\right] \mathrm{ATP}$ was performed as described in Materials and Methods. AtSERK $1^{\text {kin }}$ was incubated alone (lane 1) or with $\mathrm{KAPP}^{\mathrm{KI}}$ (lane 2) or with $\mathrm{KAPP}^{-\mathrm{SA}}$ (lane 3), or with both $\mathrm{KAPP}^{\mathrm{KI}}$ and $\mathrm{KAPP}^{-\mathrm{SA}}$ proteins (lane 4). The autoradiographs are shown. 
(Fig. 3A, lane 5). The transphosphorylation assays with AtSERK1 ${ }^{3 \mathrm{~T} \rightarrow \mathrm{E}}$ (Fig. 3A, lane 6) and AtSERK1 ${ }^{\mathrm{K} 330 \mathrm{E}}$ (Fig. $3 \mathrm{~A}$, lane 7) show results comparable to those obtained with AtSERK1 ${ }^{\mathrm{T} 468 \mathrm{~A}}$.

These results show that Thr 468 in the AtSERK1 Aloop has a major role in both the autophosphorylation activity of AtSERK1 and transphosphorylation activity on the KI domain of KAPP. This confirms previous work using casein and myelin basic protein (MBP) as artificial transphosphorylation targets for AtSERK1 (Shah et al. 2001a). In addition, Thr 463 also influences the transphosphorylation of the KI domain of KAPP. This is a different observation than that obtained with AtSERK1 transphosphorylation on casein and MBP, where only Thr 462 and Thr 468 have any influence on the transphosphorylation (Shah et al. 2001b). This finding implies a role of other threonine residues in the AtSERK1 A-loop in substrate phosphorylation.

To determine the protein phosphatase catalytic activity of KAPP, the full-length KAPP cDNA missing only the N-terminal signal anchor was fused to GST and expressed in E. coli. The affinity-purified KAPP protein $\left(\mathrm{KAPP}^{-\mathrm{SA}}\right)$ was incubated with matrix-bound $\left[\gamma^{-32} \mathrm{P}\right] \mathrm{ATP}$ phosphorylated AtSERK1 ${ }^{\text {kin }}$, and aliquots were taken out at different time intervals (Fig. 3B, lanes 2-6). The phosphorylated ASERK $1^{\text {kin }}$ was dephosphorylated by $\mathrm{KAPP}^{-\mathrm{SA}}$ with increased incubation time (Fig. 3B, lanes 2-5). Phosphorylated AtSERK1 ${ }^{\text {kin }}$ protein was almost completely dephosphorylated by KAPP ${ }^{-S A}$ after $4 \mathrm{~h}$ (Fig. $3 \mathrm{~B}$, lane 6). We were also interested in knowing whether the AtSERK1 $1^{\text {kin }}$ protein would phosphorylate in the presence of $\mathrm{KAPP}^{-\mathrm{SA}}$ protein. This led us to perform experiments in which we incubated affinity-purified AtSERK $1^{\text {kin }}$ alone (Fig. 3C, lane 1) with KAPP KI (Fig. 3C, lane 2) or $\mathrm{KAPP}^{-\mathrm{SA}}$ (Fig. 3C, lane 3) or with both $\mathrm{KAPP}^{\mathrm{KI}}$

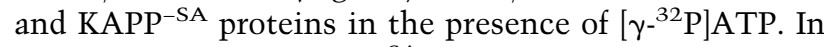
the presence of the $\mathrm{KAPP}^{-\mathrm{SA}}$ protein, there was a reduced phosphorylation of AtSERK1 ${ }^{\text {kin }}$ (Fig. 3C, lane 3) or both AtSERK $1^{\text {kin }}$ and KAPP ${ }^{\mathrm{KI}}$ (Fig. 3C, lane 4). These results demonstrate that KAPP protein not only dephosphorylates AtSERK1 protein but also actively prevents autophosphorylation of the receptor, suggesting that the KAPP protein can maintain the dephosphorylated state of AtSERK1.

\section{Colocalization of AtSERK1 and KAPP proteins in living plant cells}

Because AtSERK1 and KAPP interact in vitro, it was of interest to determine whether the two proteins are colocalized and can interact in plant cells. For this we transiently expressed in plant protoplasts two different variants of the GFP, the cyan fluorescent protein (CFP), and the yellow fluorescent protein (YFP) that are fused to the C-terminal end of AtSERK1 and KAPP protein (Fig. 1, I-L, P-U).The KAPP type 1 signal anchor (SAI) acts as an uncleaved signal peptide, resulting in cytoplasmic orientation of the membrane-anchored protein (Stone et al. 1994). To study the localization of the KAPP protein in plant protoplasts, we performed transient transfections with KAPP ${ }^{\mathrm{KI}}$-YFP, KAPP-SA-YFP, and KAPP-YFP constructs. After transfection and incubation for $12 \mathrm{~h}$, total protein was isolated, fractionated by denaturing SDSPAGE, and immunoblotted using an antiserum against GFP. The results show that all KAPP-YFP/CFP fusion proteins of the correct size are expressed in plant protoplasts (Fig. 4A). KAPP ${ }^{\mathrm{KI}}$-YFP protein showed localization in the cytoplasm (Fig. 4B), whereas KAPP-YFP protein was expressed in the plasma membrane and in the cytosol (Fig. 4C). When the protoplasts were transfected with $\mathrm{KAPP}^{-\mathrm{SA}}$-YFP, a construct in which the KAPP protein lacks the SAI signal peptide, the KAPP ${ }^{-S A}$-YFP protein was observed in the cytoplasm compartments (Fig. 4D). This shows the importance of the KAPP-SAI peptide in membrane anchoring of the KAPP protein.

In our previous studies with AtSERK1-YFP fusion protein in plant protoplasts, we showed that most of the AtSERK1-YFP protein is found in the plasma membrane and in a very small amount in endomembranes (Shah et al. 2001b). In Figure 5A, a protoplast expressing the AtSERK1-CFP is shown. CFP is represented by the cyan color and confirms the previously noted location of the AtSERK1 protein. The same protoplast was cotransfected with an ER marker (ER-YFP) that contains a Cterminal HDEL-ER retention signal fused to YFP (Fig. $5 \mathrm{~B})$. For comparison, the chlorophyll autofluorescence is shown in red (Fig. 5C). From the combined image (Fig. 5D), it is clear that ER-YFP and AtSERK1-CFP have different localizations in the protoplast. AtSERK1-CFP is seen mainly in the plasma membrane, whereas the ER at
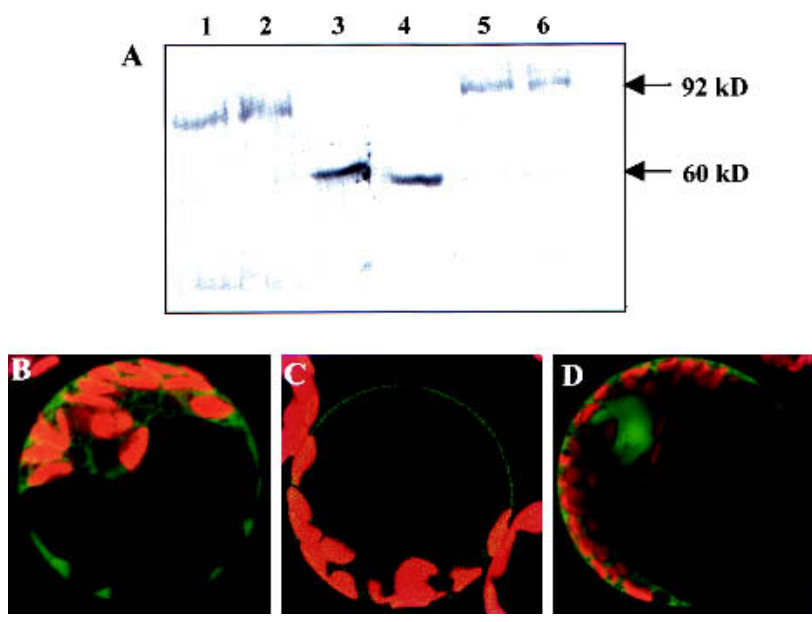

Figure 4. KAPP-CFP/YFP fusion proteins. $(A)$ Immunoblot of KAPP fusion proteins in cowpea mesophyll protoplasts. The protoplasts were harvested after $12 \mathrm{~h}$ of transfection with KAPP$\mathrm{CFP} /$ YFP transgenes, lysed, and separated on $10 \%$ reducing SDS-PAGE. Proteins transferred to nitrocellulose paper were immunoblotted with anti-GFP antibody. KAPP ${ }^{-S A}$-YFP (lane 1), $\mathrm{KAPP}^{-\mathrm{SA}}$-CFP (lane 2), KAPP ${ }^{\mathrm{KI}}$-YFP (lane 3), KAPP ${ }^{\mathrm{KI}}$-CFP (lane 4), KAPP -YFP (lane 5), and KAPP-CFP (lane 6). (B-D) Localization of KAPP proteins in cowpea mesophyll protoplasts. Chlorophyll autofluorescence is shown in red, and the YFP fluorescence is shown in green. Confocal fluorescence images of protoplasts transfected with $\mathrm{KAPP}^{\mathrm{KI}}$-YFP $(B)$, KAPP-YFP $(C)$, and KAPP_- ${ }^{-}$-YFP $(D)$. 
Shah et al.
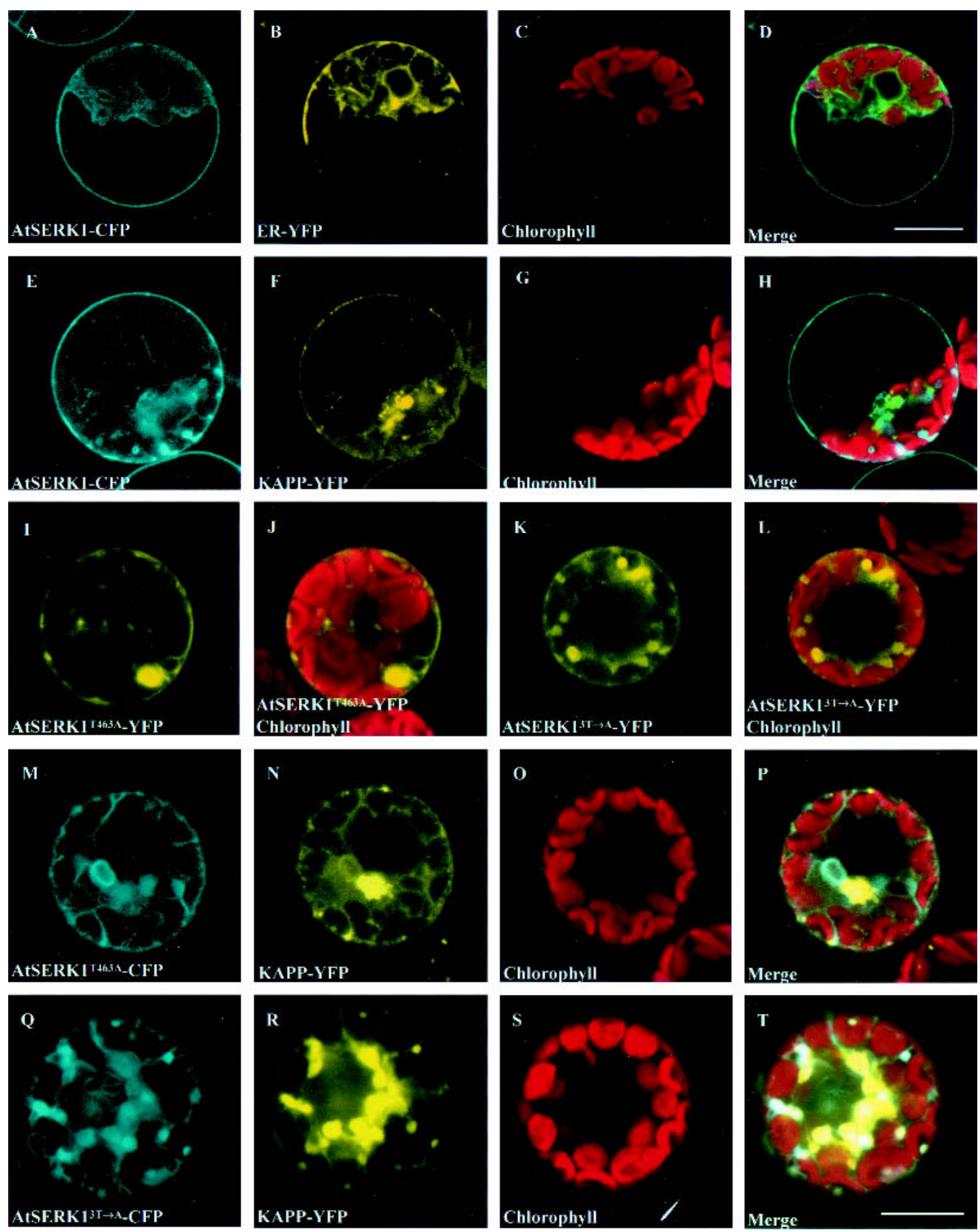

Figure 5. Colocalization of AtSERK1, AtSERK1 ${ }^{\mathrm{T} 463}, A t \mathrm{SERK} 1^{3 \mathrm{~T} \rightarrow \mathrm{A}}$, and KAPP proteins in cowpea mesophyll protoplasts. $(A-D)$ Confocal images of protoplasts cotransfected with AtSERK1-CFP and ER-YFP. The two fluorophores CFP and YFP were simultaneously visualized. AtSERK1-CFP localization is shown in cyan $(A)$. ER-YFP localization is shown in yellow $(B)$. Chlorophyll autofluorescence is shown in red $(C)$. The superimposed images of $A$ and $B$ result in $D$. $(E-H)$ Confocal images of protoplast cotransfected with KAPP-YFP and AtSERK1-CFP. The two fluorophores CFP and YFP were simultaneously visualized. Chlorophyll autofluorescence is shown in red $(G)$. Colocalization is shown in bluish green fluorescence $(H)$ resulting from the overlap of cyan $(A t S E R K 1-C F P)(E)$ and green (KAPP-YFP) $(F)$. $(I, J)$ Confocal images of the protoplasts transfected with $A t S E R K 1^{\mathrm{T} 463}$-YFP and visualized as yellow fluorescence $(I)$, and a superimposed image showing the autofluorescence of the chlorophyll $(J) \cdot(K, L)$ Confocal images of protoplasts transfected with AtSERK $1^{3 \mathrm{~T} \rightarrow \mathrm{A}}$-YFP visualized as yellow fluorescence $(K)$, and a superimposed image showing the autofluorescence of the chlorophyll $(L)$. $(M-P)$ Confocal images of protoplasts cotransfected with KAPP-YFP and AtSERK1 ${ }^{\mathrm{T} 463}$-CFP. KAPP-YFP fluorescence is shown in yellow $(N)$, and AtSERK1 ${ }^{\mathrm{T} 463}$-CFP fluorescence is shown in blue $(M)$. Chlorophyll autofluorescence is shown in red $(O)$. The superimposed images of $M$ and $N$ result in $P$. (Q-T) Confocal images of the protoplasts cotransfected with KAPP-YFP and AtSERK $1^{3 \mathrm{~T} \rightarrow \mathrm{A}}$ CFP. KAPP-YFP fluorescence is shown in yellow $(R)$, and AtSERK1 ${ }^{3 \mathrm{~T} \rightarrow \mathrm{A}}$-CFP fluorescence is shown in blue (Q). Chlorophyll autofluorescence is shown in red $(S)$. The superimposed images of $Q$ and $R$ result in $T$. Bars, $10 \mu \mathrm{m}$. 
this stage (12 $\mathrm{h}$ after transfection) is almost depleted of the AtSERK1 protein. The ER-YFP localization is visible as a complex pattern (Fig. $5 \mathrm{~B}$ ) that covers most of the cytoplasm-containing area and extends right up to the plasma membrane. It is notably excluded from the chloroplasts and the vacuole. To examine the subcellular localization of KAPP and AtSERK1 proteins together, we transiently expressed both AtSERK1-CFP and KAPP-YFP fusion proteins. When coexpressed, striking differences were noted in the localization pattern of both proteins. Substantial amounts of AtSERK1 and KAPP proteins are now seen internally (Fig. 5E-H). At the periphery of the protoplast, AtSERK1 is found in the areas that coincide with the presence of ER membranes. Substantial CFP fluorescence is also seen in a rather diffuse dotted pattern almost in the center of the cell (Fig. 5E). The KAPP protein is found mainly in the center of the cell and less in the peripheral areas (Fig. 5F). The superimposed image (Fig. $5 \mathrm{H}$ ) shows that KAPP and AtSERK1 fluorescence only substantially overlap in the central area and in the membrane. The comparison of the localization of $A t$ SERK1 and KAPP proteins (Fig. 5E,F) with the ER marker (Fig. 5B) suggests that the diffuse punctate pattern observed in the colocalization experiment might represent intracellular vesicles such as endosomes, containing internalized AtSERK1-KAPP proteins.

We next investigated whether AtSERK1 threonine residues 462, 463, and 468, involved in the interaction with KAPP (Fig. 2B) and in the transphosphorylation reaction in vitro (Fig. 3A) were involved in the observed internalization of the AtSERK1 protein. A construct containing the AtSERK1 $1^{\mathrm{T} 463 \mathrm{~A}}-\mathrm{CFP}$ fusion was localized in the plasma membrane, with a rather higher signal seen in a diffuse area in the cytoplasm compared to the AtSERK1-CFP protein (Fig. 5IJ). When AtSERK1 $1^{\text {T463A-CFP }}$ was transiently coexpressed with KAPP-YFP, substantial amounts of both proteins were found to be sequestered intracellularly (Fig. 5M,N). The AtSERK $1^{3 \mathrm{~T} \rightarrow \mathrm{A}}$-CFP protein alone localizes at the plasma membrane but is also seen internally (Fig. 5K,L), similar to what was seen for the AtSERK1 ${ }^{\mathrm{T} 463 \mathrm{~A}}-\mathrm{CFP}$ protein. Some AtSERK $1^{3 \mathrm{~T} \rightarrow \mathrm{A}_{-}}$ CFP protein was also seen to be present in the ER, suggesting an additional effect of removing the three threonines on the correct secretion of the receptor via the Golgi. Cotransfection of AtSERK $1^{3 \mathrm{~T} \rightarrow \mathrm{A}}$-CFP and KAPPYFP did not change the pattern seen for the AtSERK $1^{3 \mathrm{~T} \rightarrow \mathrm{A}}$-CFP mutant alone (Fig. 5Q-T). However, the amount of internalized AtSERK $1^{3 \mathrm{~T} \rightarrow \mathrm{A}}$-CFP protein was increased compared with the AtSERK1 ${ }^{\mathrm{T} 463 \mathrm{~A}}-\mathrm{CFP}$ alone.

We conclude that KAPP and AtSERK1 colocalize to a certain extent. Preventing a biochemical or physical interaction by removing the potential KAPP substrate threonines in the A-loop of AtSERK1 resulted in a marked intracellular localization of the receptor. Coexpressing the mutant fusion proteins along with KAPP protein enhanced the fraction of internalized receptors. This suggests that KAPP-mediated dephosphorylation of the receptor is an essential step in the internalization of the entire receptor complex.
To verify that the punctate localization pattern of the two AtSERK1 mutants and of AtSERK1 when coexpressed with KAPP protein represents true endosomal localization, we simultaneously labeled the cells with FM4-64. FM4-64 is a lipophilic dye that is taken up by endocytosis when added to yeast (Vida and Emr 1995) or plant cells (Ueda et al. 2002). Protoplasts transiently expressing AtSERK1 ${ }^{\mathrm{T} 463 \mathrm{~A}}-\mathrm{YFP}$ protein were incubated with FM4-64 and viewed by confocal microscopy after 15 min. At this timepoint, FM4-64 stained only the plasma membrane (Fig. 6A-D), where it overlaps with AtSERK1 $1^{\text {T463A }}$-YFP localization. When incubated for 3 h, FM4-64 was internalized and localized in small punctate structures, similar to the early endosomal structures reported by Ueda et al. (2002). As shown in Figure 6E-H, nearly all structures stained by FM4-64 also contained AtSERK1 $1^{\mathrm{T} 463 \mathrm{~A}}-$ YFP. This suggests that the AtSERK1 ${ }^{\mathrm{T} 463 \mathrm{~A}}$. YFP protein is internalized via an endocytotic pathway.

\section{Fluorescence resonance energy transfer studies}

To directly study the physical interaction between AtSERK1 and KAPP proteins in living plant cells, the CFP and YFP fusion proteins were used as a donor-acceptor pair in FRET studies. All constructs used in this study are described in Figure 1. Our experiments were based on fluorescence spectral imaging microscopy (FSPIM) as a detection system. Spectral images were taken from small regions of the protoplasts coexpressing YFP and CFP fusion proteins, and a fluorescence emission spectrum corrected for autofluorescence was then generated. In the case of FRET, the CFP fluorescence will be quenched and the YFP fluorescence will be increased (sensitized).

For FRET to be detected reliably using FSPIM, certain prerequisites must be satisfied. These are that donor and acceptor fluorophores must be present in a ratio close to $1: 1$; the absorption of the CFP fluorescence by chlorophyll should be minimized, fusion proteins should be properly targeted, and finally the fluorophores must be oriented so as to allow close proximity when the target proteins fused to the CFP/YFP interact. We performed FRET experiments with the AtSERK1, AtSERK1 ${ }^{\text {kin }}$, $\mathrm{KAPP}$, and $\mathrm{KAPP}{ }^{\mathrm{KI}}$ fusion proteins fused to either the donor (CFP) or the acceptor (YFP) molecules. In all experiments where FRET was observed, similar changes in the fluorescence intensity ratios were observed regardless of the donor CFP being fused to AtSERK1 or to the KAPP (Figs. 7,8). This indicates that the observed increased donor/acceptor ratio is due the energy transfer between the CFP and the YFP molecules fused to AtSERK1 or KAPP proteins and not due to an unbalanced expression ratio. To avoid interference by chlorophyll absorption, FRET measurements were performed exclusively over the regions lacking chloroplasts. Because the fluorophore orientation factor cannot be corrected for, any results showing absence of FRET may not completely guarantee that no interaction occurred between those proteins.

Protoplasts were first cotransfected with either AtSERK1 $1^{\text {kin }}-\mathrm{CFP}$ and KAPPKI-YFP or AtSERK1 $1^{\text {kin }}$-YFP 
Shah et al.
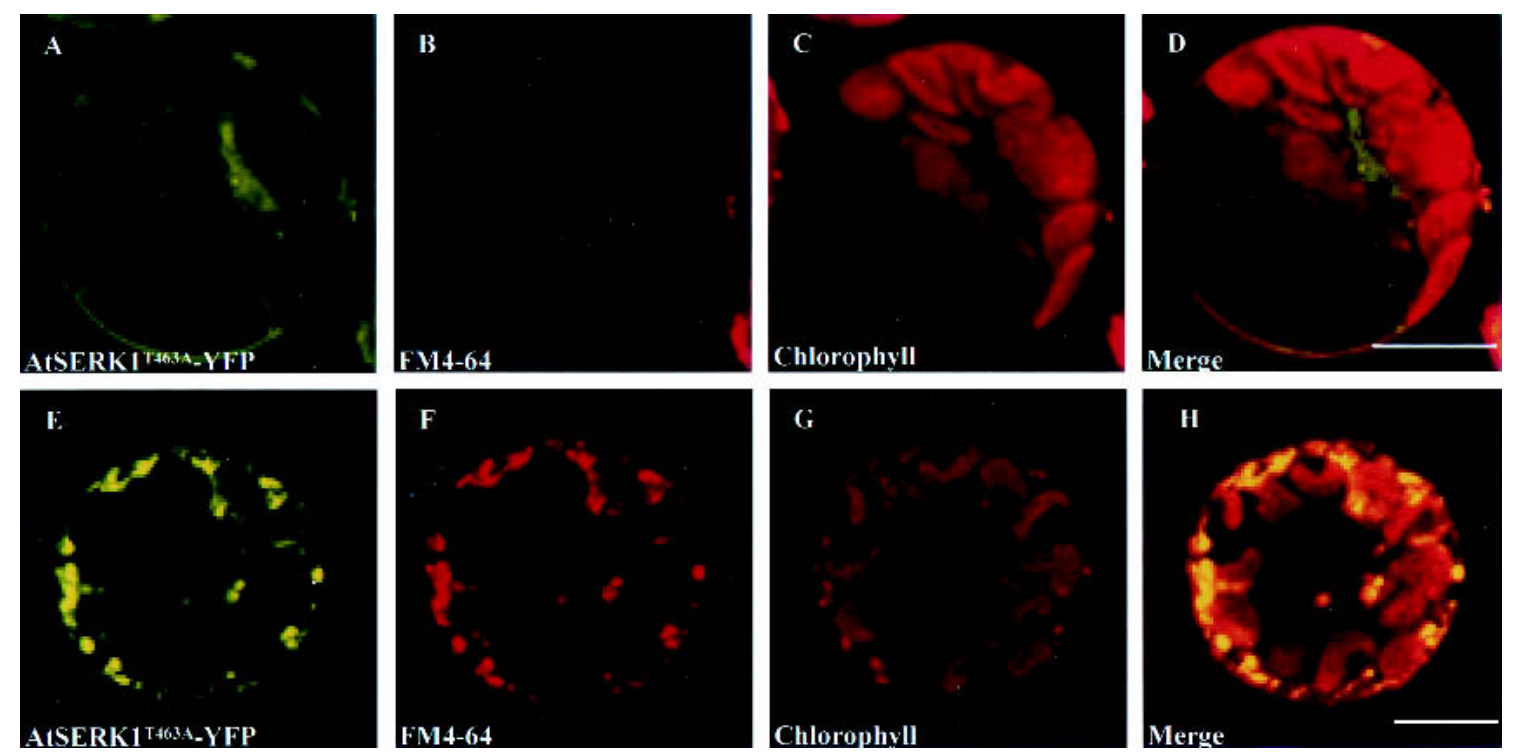

Figure 6. FM4-64 labeling. $(A-D)$ Protoplasts expressing AtSERK1 ${ }^{\mathrm{T} 463}$-YFP $(A)$ were labeled with FM4-64 and viewed after 15 min $(B)$. Chlorophyll autofluorescence is shown in red $(C)$, and the superimposed images of $A$ and $B$ result in $D$. (E-H) Protoplasts expressing $A t$ SERK1 ${ }^{\text {T463 }}$-YFP $(E)$ were labeled with FM4-64 and viewed after $3 \mathrm{~h}(F)$. Chlorophyll autofluorescence is shown in red $(G)$, and the superimposed images of $E$ and $F$ result in $H$. Bars, $10 \mu \mathrm{m}$.

and KAPP ${ }^{\mathrm{KI}}$-CFP constructs. The equal expression of the CFP and YFP fusion proteins in protoplasts was demonstrated by immunoblotting of the solubilized proteins using anti-GFP antisera (Fig. 7A). The spectral images were recorded from the different regions of the protoplasts coexpressing $A t \mathrm{SERK} 1^{\text {kin }}-\mathrm{CFP}$ and $\mathrm{KAPP}{ }^{\mathrm{KI}}-\mathrm{YFP}$ fusion proteins. The YFP/CFP fluorescence intensity ratio deduced from these spectra is over 1.5 in every 3 of 5 measurements (Fig. 7B). The YFP/CFP intensity ratio obtained from AtSERK $1^{\text {kin }}$-YFP and KAPP ${ }^{\mathrm{KI}}-\mathrm{CFP}$ cotransfected protoplasts was similar to the YFP/CFP intensity ratio shown by $A t$ SERK $1^{\text {kin }}$-CFP and KAPP ${ }^{\mathrm{KI}}$-YFP coexpressing protoplasts (Fig. 7C). When the spectra were recorded from 30 protoplasts, each coexpressing AtSERK $1^{\text {kin }}$-CFP and KAPP ${ }^{\mathrm{KI}}-\mathrm{YFP}$ or AtSERK $1^{\text {kin }}$-YFP and $\mathrm{KAPP}^{\mathrm{KI}}$-CFP, the increased YFP/CFP fluorescence intensity ratio of more than 1.5 was seen in about $80 \%$ of the measurements (data not shown). These results show that when the AtSERK $1^{\text {kin }}$ and KAPP ${ }^{\mathrm{KI}}$ proteins are in the cytoplasm, they interact physically, supporting the in vitro experiments performed on bacterially expressed proteins (see Fig. 2A)
Figure 7. Immunoblot and FSPIM analysis of fluorescent AtSERK1 ${ }^{\text {kin }}$-CFP/YFP and KAPP ${ }^{\mathrm{KI}}$ $\mathrm{CFP} /$ YFP fusion proteins. (A) Immunoblot of proteins extracted from the protoplasts cotransfected with AtSERK ${ }^{\text {kin }}{ }_{-}$CFP and KAPP ${ }^{\mathrm{KI}}$ YFP (lane 1) and AtSERK1 ${ }^{\text {kin }}$-YFP and KAPP ${ }^{\mathrm{KI}}$ CFP (lane 2). (B) Emission spectra of the AtSERK $1^{\text {kin }}$-CFP and KAPP ${ }^{\mathrm{KI}}-\mathrm{YFP}$ proteins coexpressed in protoplasts. The spectra were recorded at a position where CFP/YFP colocalization was observed in the cytoplasm. The $x$-axis gives the wavelengths of the CFP and YFP fluorophores, and the $y$-axis shows their intensities. The emission wavelengths of both CFP and YFP are shown below the graph. $(C)$ The same as $B$, for AtSERK $1^{\text {kin }}$-YFP and $\mathrm{KAPP}^{\mathrm{KI}}$-CFP-expressing protoplasts.
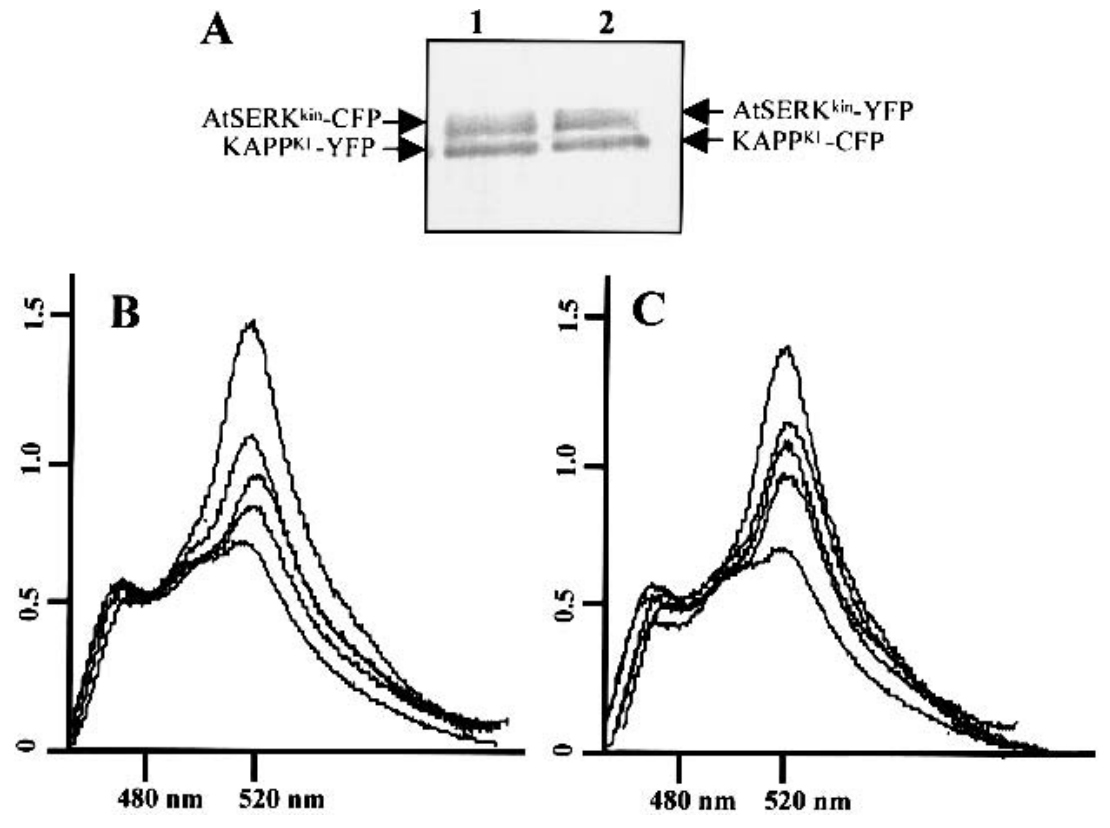

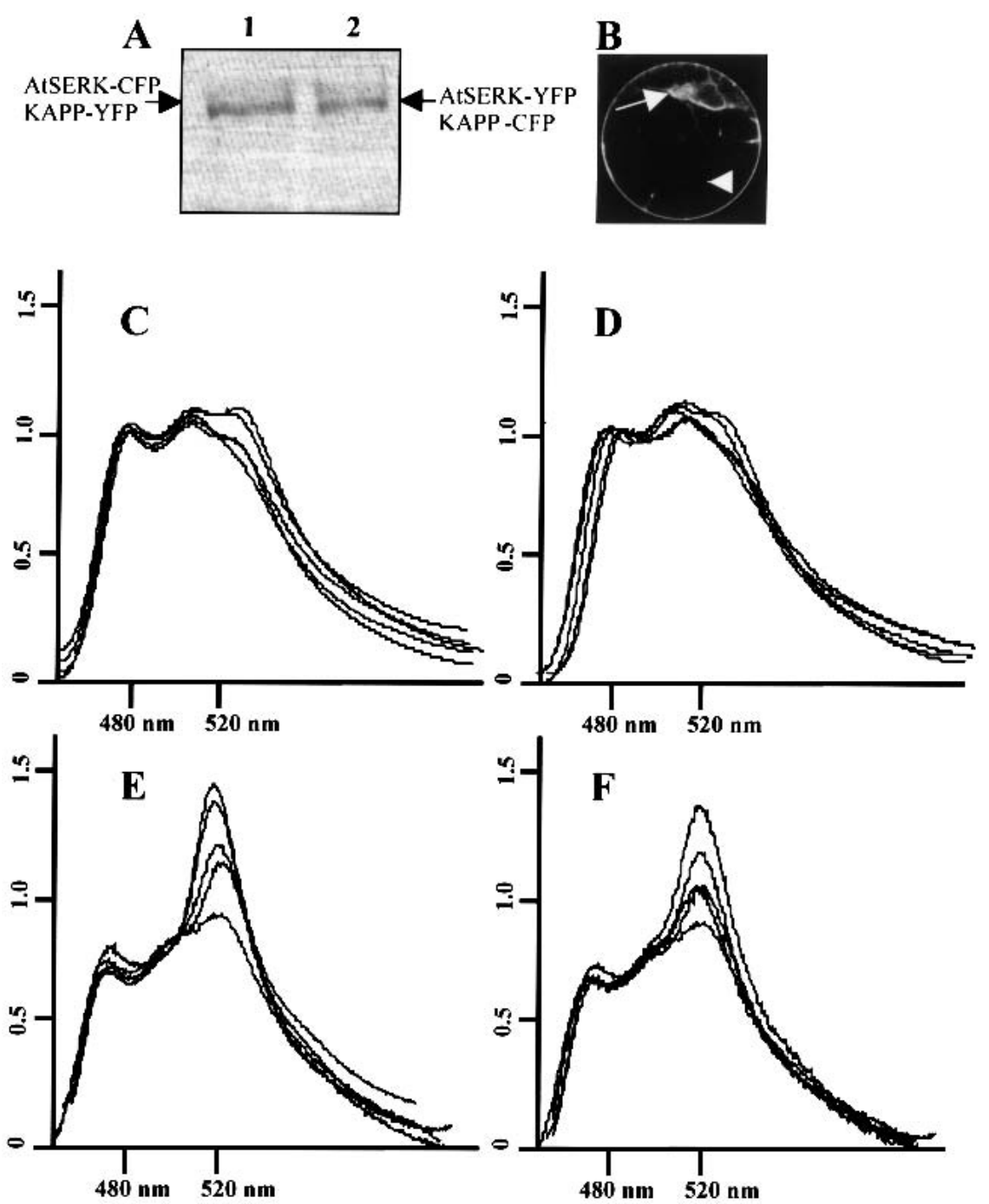

Figure 8. Immunoblot and FSPIM analysis of fluorescent AtSERK1-CFP/YFP and KAPP-CFP/YFP fusion proteins. (A) Immunoblot of proteins extracted from the protoplasts cotransfected with AtSERK1CFP and KAPP-YFP (lane 1) and AtSERK1YFP and KAPP-CFP (lane 2). (B) Emission spectra of the AtSERK1-CFP and KAPPYFP proteins obtained from the plasma membrane of coexpressed protoplasts. The spectra were recorded at a position where $\mathrm{CFP} / \mathrm{YFP}$ colocalization was observed in the plasma membrane. The $x$-axis presents the wavelengths of the CFP and YFP fluorophores, and the $y$-axis gives their intensities. The emission wavelengths of both CFP and YFP are shown below the graph. (C) The same as B, for AtSERK1-YFP and KAPP-CFP, expressing protoplasts. (D) Emission spectra of the AtSERK1-CFP and KAPP-YFP proteins obtained from the coexpressed proteins in the intracellular vesicles of protoplasts. The spectra were recorded at a position where CFP/YFP colocalization was observed intracellularly. (E) The same as $D$, for AtSERK1-YFP and KAPP-CFP-expressing protoplasts.
To determine whether physical interaction occurs between KAPP-CFP/YFP and the AtSERK1-CFP/YFP proteins, we cotransfected protoplasts with either KAPPCFP and AtSERK1-YFP or KAPP-YFP and AtSERK1-CFP constructs. The immunoblot of the coexpressed proteins using anti-GFP antisera is shown in Figure 8A. The near identical size of the AtSERK1-CFP/YFP and KAPP-CFP/ YFP fusion proteins prevents a clear distinction between two proteins on the blot. However, no gross imbalance in expression ratios is evident. We separated the FRET experiments performed on the proteins that were coexpressed at the plasma membrane and the proteins that were present intracellularly. An example of an area that was selected for recording is shown in Figure 8B, where AtSERK1 and KAPP are colocalized in the plasma membrane (shown in Fig. 8B by an arrowhead) and in the area where vesicular structures are seen (shown in Fig. 7B by an arrow). These vesicular structures are present in the cytoplasm and are distinct from the ER (as shown in Fig. 5B) and may represent endosomes as suggested by FM464 staining. In Figure 8C, spectra are shown that were obtained from protoplasts coexpressing KAPP-YFP and
AtSERK1-CFP at the plasma membrane. The YFP/CFP fluorescence intensity ratio deduced from these spectra was close to 1.0 in all of the measurements, suggesting that no interaction occurs between AtSERK1 and KAPP at the plasma membrane. The same fluorescence intensity ratios of 1.0 were obtained when protoplasts were cotransfected with KAPP-CFP and AtSERK1-YFP (Fig. $8 D)$. In about $95 \%$ of the protoplasts, the YFP/CFP fluorescence intensity ratio was close to 1.0 when the spectra were recorded at the plasma membrane from 30 protoplasts coexpressing either AtSERK1-CFP and KAPPYFP proteins or AtSERK1-YFP and KAPP-CFP proteins (data not shown). However, when the spectra were recorded on the AtSERK1-CFP and KAPP-YFP proteins (Fig. 8E) and AtSERK1-YFP and KAPP-CFP proteins (Fig. $8 \mathrm{~F})$ present intracellularly, there was a clear shift in the YFP/CFP fluorescence intensity ratio to above 1.3 and extending to 2.0 in 2 of 5 measurements. About $80 \%$ of the protoplasts showed an increased YFP/CFP fluorescence intensity ratio of about 1.4 when the spectra were recorded from 30 protoplasts coexpressing either AtSERK1-CFP and KAPP-YFP proteins or AtSERK1- 
YFP and KAPP-CFP proteins intracellularly (data not shown).

Taken together, these results led us to conclude that the kinase domain of AtSERK1 and kinase interaction domain of KAPP protein can physically interact in the cytoplasm but also do so when they are attached to their respective complete proteins as present in the internalized vesicles. Notably, no interaction appears to take place when both KAPP and AtSERK1 are present in the plasma membrane.

\section{Discussion}

Our results show that the kinase domain of AtSERK1 and the kinase interaction domain of KAPP interact in a phosphorylation-dependent manner. KAPP and AtSERK1 proteins are colocalized in plant cells at the plasma membrane and in the intracellular vesicles, but only interact physically intracellularly. Either physical or biochemical interaction between KAPP and AtSERK1 in vivo is required for receptor internalization. This finding suggests that the proposed activity of receptor-associated phosphatases such as KAPP in receptor inactivation may be tightly coupled to an internalization mechanism dependent on the A-loop phosphorylation status of the receptor. Alternatively, the presence of KAPP could reduce the extent of plasma membrane localization of the receptor by KAPP-induced blocking of the exocytotic pathway for AtSERK1. Given the reported mechanisms of down-regulation of other receptor kinases, we consider the latter explanation to be unlikely.

In animals it has been shown that a common feature of protein-protein interactions is the binding to consensus motifs containing phosphorylated residues (Yaffe et al. 1997). Phosphorylation/dephosphorylation events on plant RLKs are likely to be an important element in determining physical interaction. The KAPP protein was originally found by screening for proteins interacting with the catalytic domain of RLK5 (HAESA) (Stone et al. 1994). Subsequently it was postulated to function as a negative regulator of the CLV1 signal transduction pathway (Williams et al. 1997). KAPP is expressed throughout the shoot apical meristem (SAM) and in stage 1-2 flowers but not in stage 3 flowers, thus encompassing the region of CLV1 expression in the central cells of the SAM and young floral meristems (Williams et al. 1997). KAPP has been shown to interact with many, but not all phosphorylated RLKs (Braun et al. 1997), which implies that it recognizes a particular sequence on the target kinases. In our previous studies with the AtSERK1 protein, we showed that AtSERK1 activation requires intermolecular autophosphorylation. This presumably results in movement of the AtSERK1 A-loop, followed by release of transphosphorylation activity and protein substrate binding. In this model, A-loop phosphorylation of Thr 462 and Thr 468 of one AtSERK1 monomer is also essential for releasing catalytic activity of that same monomer. The results show that the phosphorylation status of Thr 468 is essential for AtSERK1 transphosphorylation activity on casein and MBP (Shah et al. 2001a). The fail- ure of the KAPP ${ }^{\mathrm{KI}}$ protein to bind to the AtSERK $1^{3 \mathrm{~T} \rightarrow \mathrm{E}}$ mutant shows that the conformational change of the AtSERK1 A-loop is also a prerequisite for $\mathrm{KAPP}^{\mathrm{KI}}$ binding and subsequent transphosphorylation. In contrast to the studies on casein and MBP, Thr 459 and Thr 463 also influence KAPP binding and transphosphorylation, which suggests that the A-loop is itself actively involved in the interaction with protein substrates. It is clear however that Thr 468 is the most important residue that influences not only auto- and transphosphorylation activities but also interaction with KAPP. In vivo, Thr 463 is important for internalization, presumably for its interaction with KAPP. However, it is clearly not the only residue because the $A t S E R K 1^{\mathrm{T} 463 \mathrm{~A}}$ mutant still responds to KAPP protein by acceleration of internalization.

In our studies with the KAPP ${ }^{-S A}$ protein we showed that when both $\mathrm{KAPP}^{-\mathrm{SA}}$ and $A t S E R K 1^{\mathrm{KIN}}$ proteins are incubated together, AtSERK1 phosphorylation is inhibited to a large extent. This implies that in vivo, KAPP may function by directly dephosphorylating AtSERK1, thus preventing other downstream components from receiving the AtSERK1-mediated signal. As the KAPP protein can be phosphorylated by other RLKs and also by AtSERK1, it is possible that KAPP may be modulated in response to an activated AtSERK1 receptor. However, the role of PP2C-type phosphatases and their interaction with RLKs in plants is not fully understood. The observation that binding of RLKs with KAPP is very stable and is only weakened when dephosphorylation of the RLKs by the phosphatase is completed (Li et al. 1999) suggests an intimate interaction in controlling receptor phosphorylation status.

In situ hybridization and coimmunoprecipitation studies of CLV1 and KAPP have shown that they can interact physically and biochemically. Our studies using AtSERK1 and KAPP-CFP/YFP fusion proteins have refined these observations and may have more general applications as well. The coexpressed KAPP-CFP/YFP and AtSERK1-YFP/CFP proteins were clearly colocalized in the intracellular vesicles and in the plasma membrane. However, only the KAPP-CFP/YFP and AtSERK1-YFP/ CFP protein in the intracellular vesicles interacted, whereas they did not in the plasma membrane.

In animals, receptor kinases have been shown to oligomerize, activate, autophosphorylate, and rapidly endocytose (Ullrich and Schlessinger 1990). Receptor internalization has been shown to play an important role in signaling. For example, after activation of epidermal growth factor receptor (EGFR), the receptor is internalized into acidified endosomal compartments where most of the EGFR is degraded and the excess recycled back to the plasma membrane (Wells 1999). It was recently shown that the ER-localized protein tyrosin phosphatase-1B (PTP1B) regulates dephosphorylation-dependent endocytosis of EGFR after ligand binding (Haj et al. 2002). Other PTPs may function at the plasma membrane to prevent unscheduled receptor activation. The EGFR kinase domain remains active during endocytosis (Lai et al. 1989), and certain substrates are in fact phosphorylated following internalization. To date, receptor endocytosis has not 
been described for plant RLKs, but our studies of AtSERK1 and KAPP proteins provide evidence of a novel role of the KAPP protein. Given that the KI domain of KAPP can only bind to the phosphorylated AtSERK1 protein, the observed FRET in the intracellular vesicles must derive from an interaction with the phosphorylated receptor. Notably no interaction is seen when KAPP and AtSERK1 proteins are present at the plasma membrane of the protoplasts, suggesting that the majority of the receptor molecules is in the nonphosphorylated state. At any one time, a minority of AtSERK1 protein is in the dimer state (Shah et al. 2001b). This may equate to a small number of active (phosphorylated) receptors. The phosphorylated AtSERK1 receptor may then get internalized in intracellular vesicles, reminiscent of endosomes in animal cells, a process that is clearly very much enhanced by the simultaneous presence of KAPP. Most of the AtSERK1-KAPP complex may then be degraded, while some of the AtSERK1 molecules, dephosphorylated by KAPP, can be recycled to the plasma membrane. Thus it seems plausible that internalization might play a role in extending and/or initiating signaling events at a cellular location other than the plasma membrane in plant cells as well. Studies of the phosphorylation and dephosphorylation of the receptors in living cells such as that carried out for the EGF receptor (Verveer et al. 2000) are required to reveal possible spatial selectivity in the signal transduction cascade mediated by AtSERK1.

\section{Materials and methods}

\section{GST-fusion proteins and their expression in E. coli}

The cDNA sequence encoding the AtSERK1 kinase catalytic domain, corresponding to nucleotides 1000-2068 (GenBank accession no. A67827) was amplified by PCR using the 2.1-kb cDNA cloned in vector pBluescriptII $\mathrm{SK}^{-}$as a template. All of the primers used for PCR have tailored restriction sites added. Primer SmaI1000 (5'-TCCCCCGGGTATTTTCTTCGATGTC CCTG-3') and primer NotI2068 (5'-ATAAGAATGCGGCCGC CCTTGGACCAGATA-3') amplified a PCR fragment of $1.1 \mathrm{~kb}$ that was cloned into a SmaI- and NotI-cleaved pGEX-4T1 (Pharmacia) resulting in AtSERK1 ${ }^{\text {kin }}$ construct. Site-directed mutagenesis of the highly conserved Lys 330 essential for phosphotransfer in protein kinases to glutamic acid was performed according to the manufacturer's instructions (Stratagene), resulting in the AtSERK1 ${ }^{\mathrm{K} 330 \mathrm{E}}$ construct. Site-directed mutagenesis of three threonine residues in the AtSERK1 A-loop, that is, Thr 462, Thr 463, and Thr 468 to glutamic acid residues resulted in an AtSERK $1^{3 \mathrm{~T} \rightarrow \mathrm{E}}$ construct. Single amino acid mutations of Thr 459, Thr 462, Thr 463, and Thr 468 to alanine residues resulted in AtSERK1 ${ }^{\mathrm{T} 459 \mathrm{~A}}$, AtSERK1 ${ }^{\mathrm{T} 462 \mathrm{~A}}, A t S E R K 1^{\mathrm{T} 463 \mathrm{~A}}$, and AtSERK1 $1^{\mathrm{T} 468 \mathrm{~A}}$ constructs. The cDNA sequence encoding the Arabidopsis thaliana KI domain of KAPP and the KAPP cDNA missing only the $\mathrm{N}$-terminal signal anchor was amplified by PCR using the KAPP cDNA in pBluescriptII $\mathrm{SK}^{-}$provided kindly by John C. Walker (University of Missouri-Columbia). A forward primer (5'-GGAAGATCTGGGATTTGCAGAGAC CA-3') and the reverse primer $\left(5^{\prime}\right.$-GGAAGATCTATTAGCC CCAGGAAGCGGCCA-3') amplified a PCR fragment corresponding to the KI domain of KAPP that was cloned into the
BamHI and XhoI sites of the pGEX-4T1 vector, resulting in the $\mathrm{KAPP}^{\mathrm{KI}}$ construct. To amplify the entire KAPP cDNA missing only the N-terminal signal anchor, a forward primer (5'-GGAA GATCTGGGATTTGCAGAGACCA-3') and the reverse primer (5'-GGAAGATCTCAGGGAAGTATCGAAATCTAAG-3') were used, and the 1.6-kb PCR fragment was cloned into the BamHI and XhoI sites of the pGEX-4T1 vector, resulting in the $\mathrm{KAPP}^{-\mathrm{SA}}$ construct. All plasmids were verified by restriction endonuclease digestion and DNA sequencing before being transformed into the E. coli Bl21 strain for protein expression. A 2 - $\mathrm{mL}$ overnight culture was transferred to $200 \mathrm{~mL}$ of LB medium, and the cells were grown at $37^{\circ} \mathrm{C}$ to an $O D_{600}$ of 0.6 and then induced with $0.1 \mathrm{mM}$ isopropyl-D-thiogalactopyranoside (IPTG) for $3-4 \mathrm{~h}$ at $30^{\circ} \mathrm{C}$. The cells were collected by centrifugation, resuspended in $6 \mathrm{~mL}$ of phosphate-buffered saline (PBS) lysis buffer containing protease inhibitor cocktail (Mini, Boehringer Mannheim), sonicated, and cleared by centrifugation at $12,000 \mathrm{~g}$. The soluble GST-fusion proteins were purified from the supernatant by Glutathione Sepharose 4B (Pharmacia) chromatography according to the manufacturer's instructions.

\section{Phosphorylation and dephosphorylation assays}

Transphosphorylation assays were performed by incubating 500 $\mathrm{ng}(100 \mu \mathrm{g} / \mathrm{mL})$ of either AtSERK ${ }^{\mathrm{kin}}$ or AtSERK ${ }^{\text {kin }}$ mutant proteins with $500 \mathrm{ng}$ of KAPP $\mathrm{KI}^{\mathrm{KI}}$ protein in $20 \mathrm{mM}$ Tris ( $\left.\mathrm{pH} 7.5\right), 50$ $\mathrm{mM} \mathrm{NaCl}, 0.01 \%$ Triton X-100, $10 \mathrm{mM} \mathrm{MgCl}_{2}, 1 \mathrm{mM}$ dithiothreitol (DTT), $50 \mu \mathrm{M}$ unlabeled ATP, and $10 \mu \mathrm{Ci}$ of $\left[\gamma^{-32} \mathrm{P}\right] \mathrm{ATP}$ in a final volume of $30 \mu \mathrm{L}$. After incubation for $30 \mathrm{~min}$ at $30^{\circ} \mathrm{C}$, the reaction was quenched by adding Laemmli SDS-PAGE sample buffer, boiled at $95^{\circ} \mathrm{C}$ for $5 \mathrm{~min}$, and separated by $10 \%$ SDS-PAGE. The gel was stained with Coomassie Brilliant Blue (CBB) to verify equal loading and then dried. For dephosphorylation assays, $5 \mu \mathrm{g}$ of $A t$ SERK1 ${ }^{\text {kin }}$ was phosphorylated on Glutathione Sepharose 4B (matrix), and the unbound label was washed away. The matrix-bound phosphorylated AtSERK 1 kin was treated with $5 \mu \mathrm{g}$ of $\mathrm{KAPP}^{-\mathrm{SA}}$ and incubated at $30^{\circ} \mathrm{C}$. The aliquots were taken at time intervals of 30,60, 90, 120, and 240 $\mathrm{min}$, and the reaction was quenched, proteins separated and stained, and gels were dried as described above. The radioactivity was quantified with a PhosphorImager using the ImageQuant program (Molecular Dynamics).

\section{In vitro binding assays}

Immobilized KAPP ${ }^{\mathrm{KI}}$ was phosphorylated with 10 units of bovine heart muscle kinase (Sigma) in $20 \mathrm{mM}$ Tris (pH 7.5), 50 $\mathrm{mM} \mathrm{NaCl}, 10 \mathrm{mM} \mathrm{MgCl}_{2}$ with $10 \mu \mathrm{Ci}$ of $\left[\gamma^{-32} \mathrm{P}\right] \mathrm{ATP}$ and then eluted as described above. The resulting eluent was used to probe the nitrocellulose filter prepared as described below. AtSERK1 ${ }^{\text {kin }}, A t S E R K^{\text {kin }}$ mutants, and AtSERK1 ${ }^{\text {kin }}$ treated with 25 units of alkaline phosphatase (AP) with and without AP inhibitor (Sigma) were incubated in $20 \mathrm{mM}$ Tris (pH 7.5), $50 \mathrm{mM}$ $\mathrm{NaCl}, 10 \mathrm{mM} \mathrm{MgCl}_{2}$, and $50 \mu \mathrm{M}$ unlabeled ATP in a final volume of $30 \mu \mathrm{L}$. After incubation for $2 \mathrm{~h}$ at $37^{\circ} \mathrm{C}$, the reaction was quenched by adding Laemmli SDS-PAGE sample buffer, boiled at $95^{\circ} \mathrm{C}$ for $5 \mathrm{~min}$, and separated by $10 \%$ SDS-PAGE. The proteins were transferred to a nitrocellulose filter, blocked in HBB buffer (25 mM HEPES at pH 7.5, $5 \mathrm{mM} \mathrm{MgCl}_{2}, 1 \mathrm{mM} \mathrm{KCl}$, and $5 \%$ nonfat dry milk) at $4^{\circ} \mathrm{C}$ for $4 \mathrm{~h}$, and probed overnight with $\left[\gamma^{-32} \mathrm{P}\right]$ ATP-labeled KAPP ${ }^{\mathrm{KI}}$ probe in BB buffer $(25 \mathrm{mM}$ Hepes at $\mathrm{pH} 7.5,2.5 \mathrm{mM} \mathrm{MgCl}_{2}, 7.5 \mathrm{mM} \mathrm{KCl}, 0.1 \mathrm{mM}$ EDTA and $1 \%$ nonfat dry milk). After 3 washes in BB buffer, the radioactivity of the filter was quantified with a PhosphorImager using the ImageQuant program. 


\section{Phosphoaminoacid analysis}

$\mathrm{KAPP}^{\mathrm{KI}}$ was phosphorylated by AtSERK ${ }^{\mathrm{kin}}$ in the presence of $\left[\gamma^{-}{ }^{32} \mathrm{P}\right]$ ATP and separated by SDS-PAGE as described above. The CBB-stained phosphorylated bands of $\mathrm{KAPP}^{\mathrm{KI}}$ were excised from the gel, rehydrated in $50 \mathrm{mM} \mathrm{NH}_{4} \mathrm{CO}_{3}, 0.1 \%$ SDS, and $0.25 \%$ $\beta$-mercaptoethanol (2-ME), ground with a small pestle, boiled for $5 \mathrm{~min}$, and extracted by agitation at $37^{\circ} \mathrm{C}$ for $90 \mathrm{~min}$. The proteins were precipitated by adding $20 \mu \mathrm{g}$ of BSA and $20 \%(\mathrm{w} / \mathrm{v})$ solid trichloroacetic acid (TCA) and incubated overnight at $-20^{\circ} \mathrm{C}$. The precipitate was collected by centrifugation, and the TCA was removed by lyophilization for $30 \mathrm{~min}$. The sample was hydrolyzed in $50 \mu \mathrm{L} 6 \mathrm{M} \mathrm{HCl}$ for $1 \mathrm{~h}$ at $120^{\circ} \mathrm{C}$. The $\mathrm{HCl}$ was evaporated, and the pellet was resuspended in the ascending solvent of acetic acid, ethanol, and water mixed with phosphoaminoacid standards and applied to a $10 \times 10$ cellulose TLC plate (Merck) as described by Boyle et al. (1991) using an ascending solvent for $1 \mathrm{~h}$. The first-dimension fractionation was followed by chromatography in the second-dimension in a phosphopeptide buffer containing isobutyl alcohol, glacial acetic acid, and water at 8:4:2. Phosphoaminoacid standards were visualized by spraying the plate with $0.25 \%$ ninhydrin in acetone and then heating it at $65^{\circ} \mathrm{C}$ for $30 \mathrm{~min}$. The radiographic film was exposed to the TLC plate for $12 \mathrm{~h}$, and the radioactivity was quantified with ImageQuant program (Molecular Dynamics).

\section{Construction of YFP/CFP tagged vectors}

The entire open reading frame (ORF) of the AtSERK1 cDNA was amplified by polymerase chain reaction (PCR) from an AtSERK1 full-length cDNA and cloned downstream of the $35 \mathrm{~S}$ promoter into the NcoI site of pMON999-CFP and pMON999-YFP using primers NcoI215f (5'-CATGCCATGGTGGAGTCGAGTTAT GTGG-3') and NcoI2068r (5'-CATGCCATGGACCTTGGAC CAGATAACTC-3'). This resulted in the AtSERK1-CFP and AtSERK1-YFP constructs. Thr 462, Thr 463, and Thr 468 residues in the AtSERK1-CFP and AtSERK1-YFP constructs were mutated into alanines by using a Site Directed Mutagenesis Kit (Stratagene) as described previously (Shah et al. 2001a), resulting in the AtSERK $1^{3 \mathrm{~T} \rightarrow \mathrm{A}_{-} \mathrm{CFP}}$ and AtSERK1 ${ }^{3 \mathrm{~T} \rightarrow \mathrm{A}_{-}}$-YFP constructs. The Thr 463 residue in the AtSERK1-CFP and AtSERK1-YFP constructs was also individually mutated into alanine, resulting in the AtSERK1 $1^{\mathrm{T} 463 \mathrm{~A}}-\mathrm{CFP}$ and AtSERK1 ${ }^{\mathrm{T} 463 \mathrm{~A}}$-YFP fusions.

The AtSERK1 intracellular kinase domain was similarly cloned into the NcoI site of pMON999-CFP and pMON999-YFP using primers nAtSERKC (5'-CCATCCGATGGGCCCACTA GATATTTTCTT-3') and NcoI2068r. This resulted in the AtSERK $1^{\text {kin }}$-CFP and AtSERK $1^{\text {kin }}$-YFP constructs.

The entire ORF of KAPP cDNA was amplified by PCR using primers BglKAP39f (5'-GGAAGATCTATGGCGATGATAGG GATGAAC-3') and BglTKAPr (5'-GGAAGATCTCAGGGAAG TATCGAAATCTAAG-3') and cloned into the BgIII site of pMON999-CFP and pMON999-YFP. This resulted in the KAPPCFP and KAPP-YFP constructs. A 1.6-kb cDNA fragment corresponding to the entire KAPP cDNA missing only the $\mathrm{N}$-terminal type 1 signal anchor was amplified by PCR using primers BglKIKAPnf and BglTKAPr (5'-GGAAGATCTCAGGGAAG TATCGAAATCTAAG-3') and was similarly cloned into the BgIII site of pMON999-CFP and pMON999-YFP. This resulted in the $\mathrm{KAPP}^{-\mathrm{SA}}$-CFP and $\mathrm{KAPP}^{-\mathrm{SA}}$-YFP constructs. Finally a 0.8 $\mathrm{kb}$ fragment corresponding to the KI domain of KAPP cDNA was amplified by PCR using primers BglKIKAPnf (5'-GGAA GATCTATGGGGGATTTGCAGAGACCAC-3') and BglKIKAPr (5'-GGAAGATCTATTAGCCCCAGGAAGCGGC-3') and cloned into the BglII site of pMON999-CFP and pMON999-YFP vectors. This resulted in the KAPP ${ }^{\mathrm{KI}}$-CFP and KAPP ${ }^{\mathrm{KI}}$-YFP. All constructs were verified by sequencing.
ER-YFP construct, provided kindly by Dr. Jan Carette and Dr. Joan Wellink (Wageningen University, The Netherlands), contains an $\mathrm{N}$-terminal Arabidopsis thaliana basic chitinase signal sequence and a C-terminal HDEL ER retention signal cloned downstream of the $35 \mathrm{~S}$ promoter of pMON999-YFP vector.

\section{Transient expression in protoplasts}

Cowpea mesophyll protoplasts were prepared essentially as described previously (Rezelman et al. 1989) except that $10 \mathrm{mM}$ $\mathrm{CaCl}_{2}$ was added to the enzyme solution $(0.5 \mathrm{M}$ mannitol, 10 $\mathrm{mM} \mathrm{CaCl}_{2}, 0.1 \%$ cellulase, and $0.05 \%$ pectinase). Ten to fifteen micrograms of each purified plasmid DNA was added to 0.5$1 \times 10^{6}$ protoplasts in $75-150 \mu \mathrm{L}$ of ice-cold solution C $(0.6 \mathrm{M}$ mannitol, $10 \mathrm{mM} \mathrm{CaCl}_{2}$ at $\mathrm{pH} 5.3-5.8$ ), mixed by gentle shaking and followed immediately by the addition of $0.5 \mathrm{~mL}$ of solution $\mathrm{H}$ [40\% PEG Mw 6000, 0.6 M mannitol, 0.1 M Ca( $\left.\mathrm{NO}_{3}\right)_{2}$ ]. The protoplast suspension was incubated for 5-25 sec with gentle shaking followed by the addition of $4.5 \mathrm{~mL}$ of solution $\mathrm{M}(0.5 \mathrm{M}$ mannitol, $15 \mathrm{mM} \mathrm{MgCl}_{2}$, and 0.1\% MES at $\mathrm{pH} \mathrm{5.3-5.7)} \mathrm{and}$ incubated at room temperature for $20 \mathrm{~min}$. Protoplasts were then washed 3 times with solution $\mathrm{C}$, resuspended in protoplast medium containing $0.6 \mathrm{M}$ mannitol, and incubated for $8-24 \mathrm{~h}$ as described (Rottier et al. 1979).

\section{Double labeling with AtSERK1 $1^{\text {T463A }}$-YFP and FM4-64}

Cowpea mesophyll protoplasts $12 \mathrm{~h}$ after transfection with AtSERK1 ${ }^{\mathrm{T} 463 \mathrm{~A}}$-YFP were incubated on ice for $10 \mathrm{~min}$ with 50 $\mu$ M FM4-64 (Molecular Probes). After labeling, the cells were washed twice and resuspended in protoplast medium. The protoplasts were incubated for $15 \mathrm{~min}$ to $3 \mathrm{~h}$ at $26^{\circ} \mathrm{C}$ and viewed by confocal laser microscopy.

\section{SDS-PAGE and Western blotting}

Either 1 or $2 \mathrm{~d}$ after transfection, the cowpea protoplasts were lysed in ice-cold $\mathrm{HB}$ buffer $(50 \mathrm{mM}$ Tris- $\mathrm{HCl}$ at $\mathrm{pH} 7.4,10 \mathrm{mM}$ KAc, $1 \mathrm{mM}$ EDTA, $0.05 \%$ Triton X-100) supplemented with single-strength proteinase inhibitor cocktail (Boehringer Mannheim). The lysates were passed through a $25 \mu \mathrm{m}$ needle and centrifuged at $40,000 \mathrm{~g}$ for $30 \mathrm{~min}$ at $4^{\circ} \mathrm{C}$. Ten microliters of $2 \times$ SDS sample buffer (100 mM Tris $\mathrm{HCl}$ at $\mathrm{pH}$ 6.8, 4\% SDS, $0.2 \%$ bromophenol blue, and $20 \%$ glycerol) and dithiothreitol (DTT) was added to lysates. After boiling for $3 \mathrm{~min}$, the proteins were separated by SDS-PAGE and transferred to nitrocellulose membrane (IMMOBILON) for $3 \mathrm{~h}$ at 50V. The membranes were washed in TBS-T buffer $(10 \mathrm{mM}$ Tris- $\mathrm{HCl}$ at $\mathrm{pH} 7.5,150 \mathrm{mM}$ $\mathrm{NaCl}, 0.2 \%$ Tween-20) and blocked with $5 \%$ nonfat dried milk in TBS-T for $3 \mathrm{~h}$ at room temperature, washed with TBS-T and incubated with the anti-rabbit GFP antibody (1:100 final dilution; Clontech) for $1.5 \mathrm{~h}$ at room temperature. After 3 washes in TBS-T, membranes were incubated with alkaline phosphatase conjugated anti-rabbit antibody (1:1000 final dilution; New England Biolabs). Membranes were washed in TBS-T, and incubated in Western blue substrate for Alkaline Phosphatase detection (Promega) until staining was visible.

\section{Colocalization studies using confocal microscopy}

The intracellular fluorescence and the membrane fluorescence were analyzed with a CLSM 510 confocal laser scanning microscope (Carl-Zeiss). Excitation was provided by the 458 and 514 $\mathrm{nm}$ Ar laser lines controlled by an acousto-optical tuneable filter (AOTF). Three dichroic beam splitters were used to separate excitation from emission and to divide the fluorescence emis- 
sion into the CFP, YFP, and chlorophyll channels. The HFT $458 / 514$ dual dichroic beamsplitter was used as a primary dichroic mirror reflecting excitation and transmitting fluorescence emission; an NFT 635 dichroic mirror was used as a secondary splitter, and an NFT 515 was used as tertiary dichroic splitter. Fluorescence reflected by both the NFT 635 and NFT 515 splitters was filtered through a BP $470-500 \mathrm{~nm}$ filter, yielding the CFP signal. Fluorescence reflected by the NFT 635 but transmitted by the NFT 515 splitter was filtered through a BP 535-590 nm filter, yielding the YFP channel. Fluorescence transmitted by both the NFT 515 and 635 splitters was additionally filtered by an LP 650 filter to yield the chlorophyll image. Cross-talk free CFP and YFP images were acquired by operating the microscope in the multi-tracking mode, in which the $514 \mathrm{~nm}$ excitation was coupled to activation of the YFP detection channel, and the $458 \mathrm{~nm}$ excitation was coupled to activation of the CFP and chlorophyll detection channels.

FM4-64 was excited at $548 \mathrm{~nm}$, and the emitted light was recorded at 565-595 nm. YFP fluorescence was separated from that of FM4-64 by multi-tracking. A $40 \times$ oil immersion objective (numerical aperture 1.3) was used for scanning. The pinhole setting was $60 \mu \mathrm{m}$, which yielded a theoretical thickness (full width at half-maximum) of $\sim 1 \mu \mathrm{m}$. Images and data captures were analyzed with Zeiss LSM510 software (v2.8).

\section{Fluorescence resonance energy transfer between AtSERK1 and KAPP fusion proteins}

Fluorescence resonance energy transfer (FRET) between the fluorescently labeled AtSERK1 receptors and the KAPP protein was measured by fluorescence spectral imaging microscopy (FSPIM). For SPIM, excitation was provided by a $100 \mathrm{~W}$ Hg Arc lamp of which the $435 \mathrm{~nm}$ line was selected by inserting an Omega (Brattleboro, VT) 435DF10 bandpass filter in the excitation light path. The excitation light was reflected onto the sample by an Omega 430DCLP dichroic mirror. A Leica 20x HR-fluotar air objective (NA $=0.5)$ was used. Residual excitation light was rejected using a Schott (Mainz, Germany) GG455 longpass filter. In the spectrograph (Chromex 250; Chromex, Albuquerque, NM), a 150 grooves/mm grating was used with a central wavelength of $500 \mathrm{~nm}$. For further details of the set-up, see Goedhart and Gadella (2000). Single protoplasts expressing specific CFP and YFP fusion proteins were positioned by aligning them across the entrance slit of the spectrograph (set at 200- $\mu \mathrm{m}$ width corresponding to a line of $10-\mu \mathrm{m}$ width in the object plane). Acquisition time was 1-2 sec. Regions of the image spectrum corresponding to the plasma membrane or cytosol of labeled cells were distance averaged (typically 5-10 rows of pixels), and the resulting fluorescence spectra were corrected for background fluorescence and camera bias by background subtraction using an extracellular region just next to the plasma membrane region from the same spectral image. The resulting spectra were not corrected for the spectral instrument response, yielding a slightly underestimated intensity in the blue edge of the spectra.

\section{Acknowledgments}

We thank Dr. Kevin Lease and Professor John C. Walker for the KAPP cDNA clone, and Dr. Jan Carette and Dr. Joan Wellink for the ER-YFP and ER-CFP clones. We also thank Dr. Mark Hink, Jan-Willem Borst, and Jeroen Pouwels for their help with confocal microscopy. This work was supported by grants ERBIO4CT96-2282 and ERBIO4-CT96-0689 from the EU Biotechnology Program (K.S. and E.R.) and the Royal Netherlands Academy of Sciences (T.W.J.G.).
The publication costs of this article were defrayed in part by payment of page charges. This article must therefore be hereby marked "advertisement" in accordance with 18 USC section 1734 solely to indicate this fact.

\section{References}

Boyle, W.J., van der Geer, P., and Hunter, T. 1991. Phosphopeptide mapping and phosphoamino acid analysis by two-dimensional separation on thin-layer cellulose plates. Methods Enzymol. 201: 10-49.

Braun, D.M, Stone, J.M., and Walker, J.C. 1997. Interaction of the maize and Arabidopsis kinase interaction domains with a subset of receptor-like protein kinases: Implications for transmembrane signalling in plants. Plant J. 12: 83-95.

Carey, K.L., Richards, S.A., Lounsbury, K.M., and Macara, I.G. 1996. Evidence using a green fluorescent protein-glucocorticoid receptor chimera that the Ran/TC4 GTPase mediates anessential function independent of nuclear protein import. J. Cell Biol. 133: 985-996.

Clark, S.E., Williams, R.W., and Meyerowitz, E.M. 1997. The CLAVATA1 gene encodes a putative receptor kinase that controls shoot and floral meristem size in Arabidopsis. Cell 89: 575-585.

Cohen, P. 1989. Structure and regulation of protein phosphatases. Annu. Rev. Biochem. 103: 211-225.

Cohen, P.T.W. 1997. Novel protein serine/threonine phosphatases: Variety is the spice of life. Trends Biochem. Sci. 22: $245-251$.

Gadella, Jr., T.W.J., Van der Krogt, G.N.M., and Bisseling, T. 1999. GFP-based FRET microscopy in living plant cells. Trends Plant Sci. 4: 287-291.

Gerdes, H.H. and Kaether, C. 1996. Green fluorescent protein: Applications in cell biology. FEBS Lett. 389: 44-47.

Goedhart, J. and Gadella, Jr., T.W.J. 2000 Advanced fluorescence microspectroscopic methods for the study of single living root hairs. In Root hairs: Cell and molecular biology (eds. R.W. Ridge and A.M.C. Emons), pp. 65-94. Springer-Verlag, Tokyo.

Haj, F.G., Verveer, P.J., Squire, A., Neel, B.G., and Bastianens, P.I.H. 2002. Imaging sites of receptor dephosphorylation by PTP1B on the surface of the endoplasmic reticulum. Science 295: 1708-1711.

Hecht, V., Vielle-Calzada, J.P., von Recklinghausen, I., Hartog, M.V., Schmidt, E.D.L., Boutilier, K., Grossniklaus, U., and de Vries S.C. 2001. The Arabidopsis SOMATIC EMBRYOGENESIS RECEPTOR KINASE 1 gene is expressed in developing ovules and embryos and enhances embryogenic competence in culture. Plant Physiol. 127: 803-816.

Jovin, T.M. and Arndt-Jovin, D.J. 1989. Luminescence digital imaging microscopy. Annu. Rev. Biophys. Chem. 18: 271308.

Lai, W.H., Cameron, P.H., Wada, I., Doherty, J.J., Kay, D.G., Posner, B.I., and Bergeron, J.J. 1989. Ligand-mediated internalization, recycling, and downregulation of the epidermal growth factor receptor in vivo. J. Cell Biol. 109: 2741-2749.

Li, J. and Chory, J. 1997. A putative leucine-rich repeat receptor kinase involved in brassinosteroid signal transduction. Cell 90: 929-938.

Li, J., Smith, G.P., and Walker, J.C. 1999. Kinase interaction domain of kinase-associated protein phosphatase, a phosphoprotein-binding domain. Proc. Natl. Acad. Sci. 96: 78217826.

Ludin, B., Doll, T., Meili, R., Kaech, S., and Matus, A. 1996. Application of novel vectors for GFP-tagging of proteins to study microtubule-associated proteins. Gene 173: 107-111. 
Shah et al.

Rezelman, G., van Kammen, A., and Wellink, J. 1989. Expression of cowpea mosaic virus mRNA in cowpea protoplasts. J. Gen. Virol. 70: 3043-3050.

Rizzuto, R., Brini, M., De Giorgi, F., Rossi, R., Heim, R., Tsien, R.Y., and Pozzan, T. 1996. Double labelling of subcellular structures with organelle-targeted GFP mutants in vivo. Curr. Biol. 1: 183-188.

Rottier, P.J, Rezelman, G., and van Kammen, A. 1979. The inhibition of cowpea mosaic virus replication by actinomycin D. Virology 92: 299-309.

Schmidt, E.D.L., Guzzo, F., Toonen, M.A.J., and de Vries, S.C. 1997 A leucine rich repeat containing receptor-like kinase marks somatic plant cells competent to form embryos. Development 124: 2049-2062.

Shah, K., Vervoort, J., and de Vries S.C. 2001a. Role of threonines in the AtSERK1 activation loop in phosphorylation. J. Biol. Chem. 276: 41263-41269.

Shah, K., Gadella, T.W.J., van Erp, H., Hecht, V., and de Vries S.C. 2001b. Subcellular localization and dimerization of the A. thaliana somatic embryogenesis receptor kinase 1 protein. J. Mol. Biol. 309: 641-655.

Shenolikar, S. and Nairn, A.C. 1991. Protein phosphatases: Recent progress. Adv. Sec. Messenger Phosphoprotein Res. 23: $1-121$.

Sorkin, A., McClure, M., Huang, F., and Carter, R. 2000. Interaction of EGF receptor and grb2 in living cells visualized by fluorescence resonance energy transfer FRET microscopy Curr. Biol. 10: 1395-1398.

Stone, J.M, Collinge, M.A., Smith, R.D., Horn, M.A., and Walker, J.C. 1994. Interaction of a protein phosphatase with an Arabidopsis serine-threonine receptor kinase. Science 266: 793-795.

Stone, J.M., Trotochaud, A.E., Walker, J.C., and Clark, S.E. 1998. Control of meristem development by CLAVATA1 receptor kinase and kinase-associated protein phosphatase interactions. Plant Physiol. 117: 1217-1225.

Torii, K.U. 2000. Receptor kinase activation and signal transduction in plants: An emerging picture. Curr. Opin. Plant Biol. 3: 361-367.

Torii, K.U., Mitsukawa, N., Oosumi, T., Matsuura, Y., Yokoyama, R., Whittier, R.F., and Komeda, Y., 1996. The Arabidopsis ERECTA gene encodes a putative receptor protein kinase with extracellular leucine-rich repeats. Plant Cell 8: 735-746.

Trotochaud, A.E., Hao, T., Wu, G., Yang, Z., and Clark, S.E. 1999. The CLAVATA1 receptor-like kinase requires CLAVATA3 for its assembly into a signalling complex that includes KAPP and a Rho-related protein. Plant Cell 11: 393-406.

Ueda, T., Yamaguchi, M., Uchimiya H., and Nakano, A. 2002. Ara6, a plant-unique novel type Rab GTPase, functions in the endocytic pathway of Arabidopsis thaliana. EMBO $\mathrm{I}$. 20: $4730-4741$.

Ullrich, A. and Schlessinger, J. 1990. Signal transduction by receptors with tyrosine kinase activity Cell 61: 203-212.

Verveer, P.J., Wouters, F.S., Reynolds, A.R., and Bastiaens, P.I. 2000. Quantitative imaging of lateral ErbB1 receptor signal propagation in the plasma membrane. Science 290: 15671570.

Vida, T.A. and Emr, S.D. 1995. A new vital stain for visualizing vacuolar membrane dynamics and endocytosis in yeast. $J$. Cell Biol. 128: 779-792.

Wells, A. 1999. EGF receptor. Int. J. Biochem. Cell Biol. 31: 637-643.

Williams, R.W., Wilson, J.M., and Meyerowitz, E.M. 1997. A possible role for kinase associated protein phosphatase in the
Arabidopsis CLAVATA1 signalling pathway. Proc. Nat1. Acad. Sci. 94: 10467-10472.

Yaffe, M.B., Rittinger, K., Volinia, S., Caron, P.R., Aitken, A., Leffers, H., Gamblin, S.J., Smerdon, S.J., and Cantley, L.C. 1997. The structural basis for 14-3-3:phosphopeptide binding specificity. Cell 91: 961-971. 


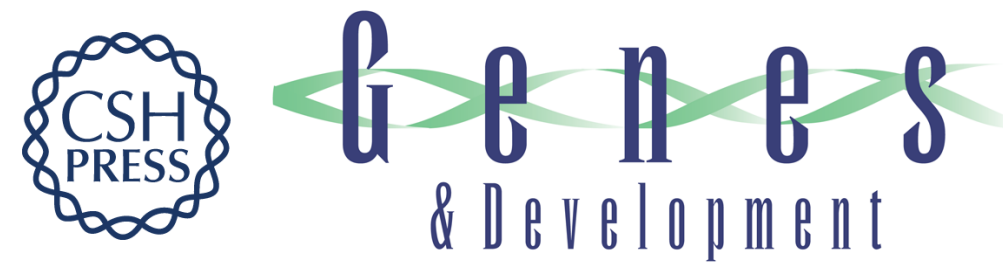

\section{The Arabidopsis kinase-associated protein phosphatase controls internalization of the somatic embryogenesis receptor kinase 1}

Khalid Shah, Eugenia Russinova, Theodorus W.J. Gadella, Jr., et al.

Genes Dev. 2002, 16:

Access the most recent version at doi:10.1101/gad.220402

References This article cites 34 articles, 15 of which can be accessed free at:

http://genesdev.cshlp.org/content/16/13/1707.full.html\#ref-list-1

License

Email Alerting Receive free email alerts when new articles cite this article - sign up in the box at the top Service right corner of the article or click here.

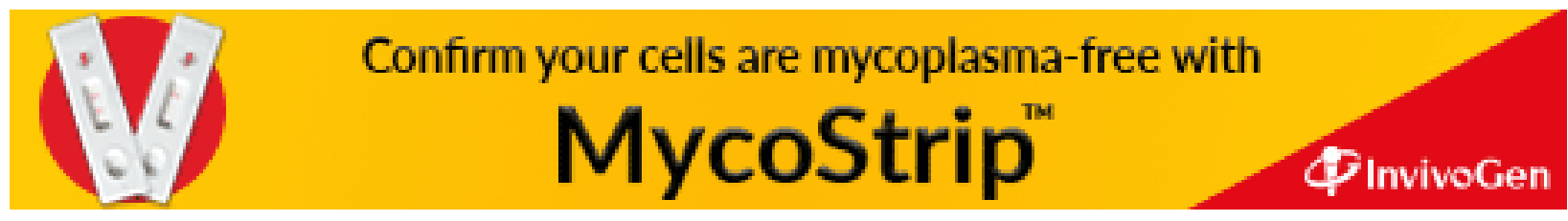

